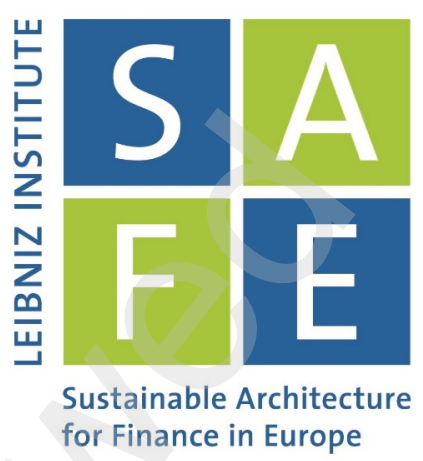

Ruggero Jappelli | Loriana Pelizzon | Alberto Plazzi

\title{
The Core, the Periphery, and the Disaster: Corporate-Sovereign Nexus in COVID-19 Times
}

SAFE Working Paper No. 331 | December 2021

\section{Leibniz Institute for Financial Research SAFE Sustainable Architecture for Finance in Europe}




\title{
The Core, the Periphery, and the Disaster: Corporate-Sovereign Nexus in COVID-19 Times
}

\author{
RUGGERO JAPPELLI*,LORIANA PELIZZON, AND ALBERTO PLAZZI ${ }^{\S}$
}

October 20, 2021

\begin{abstract}
We show that the COVID-19 pandemic triggered a surge in the elasticity of non-financial corporate to sovereign credit default swaps in core EU countries, characterized by strong fiscal capacity. For peripheral countries with lower budgetary slackness, the pandemic had essentially no impact on such elasticity. This evidence is consistent with the disaster-induced repricing of government support, which we model through a rare-disaster asset pricing framework with bailout guarantees and defaultable public debt. The model implies that risk-adjusted guarantees in the core were 2.6 times those in the periphery, suggesting that fiscal capacity buffers provide relief to firms' financing costs.
\end{abstract}

JEL classification: F65, G01, G15

Keywords: COVID-19, Credit Risk, Sovereign Risk, Fiscal Capacity, Bailout.

\footnotetext{
*Leibniz Institute for Financial Research SAFE, Goethe University Frankfurt, Theodor-W.-Adorno-Platz 3, 60323, Frankfurt am Main, Germany, jappelli@safe-frankfurt.de.

\Leibniz Institute for Financial Research SAFE, Goethe University Frankfurt, Theodor-W.-Adorno-Platz 3, 60323, Frankfurt am Main, Germany, Ca' Foscari University of Venice, Dorsoduro, 3246, 30123 Venezia, Italy and CEPR, pelizzon@ safe.uni-frankfurt.de.

§Institute of Finance, Università della Svizzera Italiana and Swiss Finance Institute, Via Buffi 13, Lugano, Switzerland, alberto.plazzi@usi.ch. We are particularly indebted to Viral Acharya, Patrick Augustin, Stephen Schaefer, and Marti G. Subrahmanyam for insightful discussions and feedback. We also thank Pasquale della Corte, Marco Di Maggio, Denis Gromb, Yueran Ma, Florian Nagler, Marco Pagano, Christian Schlag, Mark M. Spiegel, and seminar participants at the CEAR-CenFIS Workshop, the EFA Meetings, Goethe University Frankfurt, LTI@UniTO, the University of Naples Federico II, the Swiss Finance Institute, and the University of Verona for comments.
} 


\section{Introduction}

How do sovereign and domestic corporate credit risk interact with each other? For financial firms, most notably banks, a fundamental characterization of the channels at play has been established through the "doom loop" (see, e.g., Acharya et al., 2014; Brunnermeier et al., 2016; Farhi and Tirole, 2018). There is also empirical evidence that credit risk spillovers take place between the sovereign and the domestic non-financial sectors (see, e.g., Lee et al., 2016; Almeida et al., 2017). The sobering message from this literature is that a rise in sovereign risk generates negative externalities on the ability of corporations to service their debt obligations, and hence on their creditworthiness. These externalities are generally deemed to be exacerbated in governments with already low fiscal space and high credit spreads, for which a further deterioration in credit conditions would raise concerns of future increases in corporate taxes and more generally a disruption in the legal, political, and economic framework (Corsetti et al., 2013; Augustin et al., 2018). This paper shows that, in the face of a tail event episode, this prediction is not supported by the data. In fact, the contrary holds, as countries with wider fiscal space experience a strengthening in corporate-sovereign credit risk transfers. We offer an explanation of this result through a disaster-risk asset pricing model with bailout guarantees.

It is well known that credit risk markets often experience sudden run-ups in spreads (Pan and Singleton, 2008). A notable example occurred at the COVID-19 outbreak, when investors swiftly repriced the cost of default insurance as soon as governments imposed widespread and unprecedented halts to economic activity. In the cross section of countries in the European Union (EU), the first Western countries hit by the pandemic, five-year credit default swap (CDS) spreads on both sovereign and corporate entities experienced a massive surge. This pattern characterizes both core EU countries with strong public finances and peripheral EU member states, where the volume of outstanding public debt and its financing costs are more concerning. The unanticipated and clearly exogenous nature of the pandemic shock makes it an ideal environment for testing the role of fiscal space in shaping the corporate-sovereign credit risk loop.

We find that the sensitivity of CDS spreads referencing non-financial corporations to those 
on the corresponding governments, which we term the "corporate-sovereign nexus," increased in the period following the first Italian lockdown (February 24, 2020) only in the core of the EU; namely, in countries with strong fiscal capacity. For this group of countries - Belgium, Finland, France, Germany, and the Netherlands - the pandemic had an economically large and statistically significant positive impact on the nexus. By contrast, in peripheral EU countries (e.g., Greece, Italy, Portugal, and Spain) the effect of the pandemic on the nexus was, albeit positive, small and not statistically significant. Overall, by September 2020, we observe a complete alignment in the sensitivity of corporate CDS spreads to their sovereigns between the two groups of countries to a value of about 0.25 ; namely, a $10 \%$ increase in sovereign spreads is accompanied by an expected $2.5 \%$ increase in corporate credit spreads.

A strengthening of the interplay between corporate and sovereign credit risk for fiscally robust countries is consistent with market participants factoring the effectiveness of implicit or explicit government guarantees into the pricing of corporate claims. Given that core EU countries have greater fiscal maneuverability space, this backstop option has the potential to amplify the reliance of the credit risk of domestic firms on their sovereigns in the core of the EU. As a formal test of this "bailout channel," we closely follow Kelly et al. (2016), who study the pricing of financial firms during the 2007-2009 Crisis by relating the difference between actual CDS spreads and those implied by a standard structural model of default to firm size. After the Italian lockdown, we detect systematic departures between observed and theoretical spreads that are a decreasing function of firm size only for companies headquartered in core countries. On the other hand, size does not explain deviations from fundamentals in the periphery. This differential role of size in predicting deviations from fundamental credit risk in the two groups of countries lends support to the argument that fiscal space is a key driver of the sensitivity of corporate to sovereign credit risk via the investor perceptions of the strength of government guarantees. In a similar vein, our baseline regression estimates of the nexus strengthen when we weight observations by market capitalization.

Overall, a novel implication of our empirical analysis is that the corporate-sovereign nexus 
is not necessarily a concerning characteristic of debt (credit risk) markets. Rather, credit risk transfers between corporate and public debt could reflect the pricing of public guarantees, which are reassessed when a tail event materializes and are credible only for countries with sufficient fiscal space.

From a methodological perspective, our results are obtained in a panel setup, where we control for a number of factors, including the firm's equity return, aggregate volatility and fixed effects. The equity return in particular should absorb the effect of aggregate shocks on both firm assets and sovereign creditworthiness that could bias our inference (Acharya et al., 2014). Moreover, our focus on EU countries provides us with an ideal setting, as monetary policy, exchange rates, and (to a large extent) pandemic intensity are homogeneous.

We are aware that our empirical design could be capturing channels and differences between core and periphery that are unrelated to fiscal space. We thus augment our setting with firm-level characteristics - firm profitability, liquidity, and financing structure - that have been shown to trigger a differential response to the shock in the cross section of firms. Similarly, we control for country-level proxies for the resilience to COVID-19 and the severity of the shock. Finally, we account for imbalances between core and periphery in the distribution of covariates and in sample size and industrial structure. We find that our conclusions are robust to all these and a number of other specification tests. The heightening of the corporate-sovereign nexus is particularly strong for firms in COVID-sensitive sectors. It is pervasive across all core countries and conversely muted across all peripherals, which indicates that the core/periphery grouping is well representative of the disaggregated cross section. We also verify that our findings continue to hold for firms whose bonds were not targeted by the ECB's Pandemic Emergency Purchase Programme (a "monetary policy channel"), for firms whose CDS spread was below that of their sovereign counterparts at the inception of the pandemic (an "exodus from sovereign ceiling" channel, as in Lee et al., 2016), for companies with either above- or below-average government ownership (a "direct ownership channel"), and if we restrict the COVID-19 sample to the month following the Italian lockdown, when discussions about the European Recovery Fund were yet to reach the market (a "demand 
channel").

In sum, the data point toward the pivotal role of a country's fiscal space in the repricing of credit risk in the face of the pandemic. We formalize this result in an asset pricing model that integrates sovereign risk and the pricing of corporate claims. The model features the following three ingredients. First, we resort to the standard intensity-based approach to credit risk (see, among others, Longstaff et al., 2005), as it provides us with a common framework for the pricing of corporate and sovereign claims. Second, we capture the gist of the reaction to the COVID-19 pandemic through a rare-event model with time-varying probability of a disaster, whose magnitude is stochastic as in Gabaix (2012). In our setup, a disaster consists of a negative jump in consumption and a positive jump in default intensity. The probability of a rare event follows a persistent Markov process. This implies that the one-time occurrence of a disaster has long-lasting consequences on the pricing of credit risk.

Third, we allow fiscal capacity buffers to affect market prices via the ability of the government to grant collective guarantees to the domestic sector. More specifically, market participants expect the government to activate those guarantees when it deems the size of the jump in corporate intensity of default too large. We model such guarantees as a ceiling on the size of the jump, as in Kelly et al. (2016) and Gandhi et al. (2020). We enrich their framework by accounting for riskbearing government debt, meaning that the activation of the guarantee determines an increase in the default risk of public debt equal to the portion of the shock that the government absorbed. This extension allows us to study the structural drivers of the relation between corporate and sovereign credit spreads.

The model delivers closed-form expressions for the covariance between changes in default intensities of government and domestic corporations and, to an approximation, changes in their CDS spreads. Conditionally on the disaster taking place, the covariance increases with the strength of the government guarantee. This implies that, all else constant, countries with broader fiscal space should experience a stronger increase in the nexus, consistent with our empirical findings. The covariance also increases with the sensitivity of a firm's credit risk to contraction and hence to 
government intervention.

To tease out how these two components - the size of the bailout and firm sensitivity - compare between core and periphery, we rely on the synthetic control method of Abadie et al. (2010), which is also used by Almeida et al. (2017) to study sovereign risk spillovers. We construct "synthetic spreads" for companies in a region (say, core) by matching them during the pre-COVID sample with firms in the other region (periphery) on standard variables capturing credit risk. The method allows us to evaluate the difference between actual (i.e., treated) spreads and a portfolio of spreads (control group) that are subject to the same level of guarantees but have different sensitivity to bailout.

This analysis delivers a number of insights. The treated and control CDS series are very similar in the pre-COVID sample but diverge thereafter, with spreads on synthetic core firms being on average higher than those of peripheral firms. This implies that, as the disaster unfolds, credit risk in the two groups of firms is priced differently. It also reveals that corporate credit risk is more sensitive to sovereign support in the core than in the periphery. In other words, when the disaster looms, corporate credit risk responds strongly to the pricing of public intervention in countries whose governments are regarded to be better positioned to provide a solid backstop option. Finally, based on our modelling framework, comparing synthetic and actual spreads delivers an estimate of the pricing impact of fiscal capacity as measured by the ratio of CSD-implied bailout guarantees in the two regions. We find that, in risk-adjusted terms, guarantees are 2.6 times larger in the core than in the periphery, which indicates that firms in core EU countries benefitted from a milder increase in their spreads compared to those in the periphery thanks to the perception of a more effective support.

Our findings have broad implications in light of the debate around the benefits of fiscal capacity. Recently, Blanchard (2019) argues that in a low interest rate environment, high public debt may not imply large fiscal costs. However, provided markets are informationally efficient, our analysis uncovers a positive effect originating from sovereign fiscal space, as spending capacity buffers directly spill over to corporate credit risk following disaster-induced repricing. Ultimately, this 
effect lowers corporate credit spreads - and hence the cost of capital - for companies headquartered in fiscally sound countries, thereby increasing their resiliency.

Related Literature: Our work builds on the literature that studies the pass-through of risk between sovereigns and firms. A large body of literature has focused on the "doom loop" between the sovereign and the banking sector. Acharya et al. (2014), Bocola (2016), Brunnermeier et al. (2016), and Mäkinen et al. (2020) provide prominent theoretical and empirical frameworks to understand this relation. By contrast, the nexus between the public and non-financial corporate sector has received comparably less attention. Credit risk spillovers to domestic non-financial firms are discussed in, among others, Almeida et al. (2017), who exploit variation in credit ratings and investigate the real effects of rating agencies' sovereign ceiling policies, and Bevilaqua et al. (2020), who use bond yields and suggest that the relation might be state dependent and driven by an information channel. Notable contributions in this area that rely on CDS spreads as a measure of credit risk include Bedendo and Colla (2015), Lee et al. (2016), and Augustin et al. (2018). Unlike their work, our focus is on how the corporate-sovereign nexus changes in the face of a rare disaster. Corsetti et al. (2013) modify the standard neo-Keynesian framework by allowing sovereign default risk to impact funding costs in the private sector over concern for tax hikes and disruptive strikes and calibrate the model on CDS data. What differentiates our modelling approach from theirs is the analysis of the pricing of government guarantees within an intensity-based asset pricing framework.

We naturally connect to the growing number of studies on the effects of the pandemic on financial markets. Among others, Augustin et al. (2021) document that sovereign credit risk in countries with more fiscal space is relatively less sensitive to the COVID-19 pandemic. We provide complementary evidence by investigating the relation between sovereign and corporate debt credit risk, on top of the response of equity returns, and offer a theoretical framework to interpret it. Unlike their study, we do not rely on observable metrics of fiscal space. Rather, we look directly at the market recognition of the expected effectiveness of government guarantees (which reflect fiscal slackness and the sustainability of debt) as priced into credit derivatives. Gerding et al. (2020) find 
that a country's debt-to-GDP ratio is a strong determinant of domestic stock market reaction to the outbreak. ${ }^{1}$ By studying credit markets through the lenses of a rare-disaster model, we are able to quantify the benefits of fiscal space for the cost of capital, as measured by the value of government guarantees implicit in credit spreads.

Elenev et al. (2020) carry a quantitative comparison of the impact of direct debt purchases, guarantees on credit provision, and a combination thereof in mitigating US corporate credit risk during the pandemic through a macroeconomic model with financial frictions. By contrast, we provide an international perspective on guarantees in a group of countries with a common currency but differently perceived government space of maneuver.

Finally, we relate to the literature on disaster models (see Rietz, 1988; Barro, 2006; Gabaix, 2012). Pagano et al. (2020) test the predictions of disaster models on equity prices during the COVID-19 pandemic. By contrast, we extend the bailout-augmented disaster model of Kelly et al. (2016) and Gandhi et al. (2020) by considering the implications of the pricing of bailout guarantees on the relation between corporate and sovereign debt.

\section{Data and hypotheses development}

Section 2.1 describes the data and provides summary statistics, and Section 2.2 outlines the hypotheses that form the basis for our empirical analyses.

\subsection{Data and summary statistics}

We focus on how credit default swap (CDS) spreads of major European corporate (i.e., nonfinancial) firms relate to spreads referencing their sovereigns. CDS are standardized contracts providing insurance against default of a reference entity in exchange for a premium in basis points (bps) per year as a fraction of the underlying notional (Duffie, 1999). If default takes place, the

\footnotetext{
${ }^{1}$ Along similar lines, Greppmair et al. (2020) suggest that short sellers made profits on companies located in financially weak countries, anticipating
} the importance of a country's fiscal space for the resiliency of its domestic firms. 
insurance buyer is entitled to sell the underlying at face value to the insurance seller. ${ }^{2}$

Our source for the CDS data is Markit. The working sample consists of daily mid-quotes from January 1, 2019 to September 10, 2020 (443 trading days) and covering the following nine European countries: Belgium, Finland, France, Germany, and the Netherlands, which we label as core of the EU, and Greece, Italy, Portugal, and Spain, which we refer to as periphery of the EU, following the classification in Ehrmann and Fratzscher (2017). The sample selection follows Ang and Longstaff (2013), conditional on data availability for corporate CDS. ${ }^{3}$ The focus on European Monetary Union countries anchored to a common currency but unable to take independent re- or de-valuation decisions minimizes concerns about the effect of strategic devaluation on credit risk. The inclusion of other countries, on the other hand, could bias our estimates. ${ }^{4}$

As is standard in the literature, we work on spreads on CDS contracts with five-year tenor (the most liquid) that reference senior unsecured debt and denominated in Euros. For sovereigns, we rely on cum-restructuring (CR 2014 protocol) instruments, which is the standard reference for Western European sovereign CDS contracts. Corporate CDS data availability leads to the selection of the modified-modified restructuring clause (MMR), but our results are robust to the choice of the clause..$^{5}$ To include a company in the analysis, we require availability of equity data on Refinitiv, from which we also gather credit ratings and balance sheet data (such as market capitalization, leverage, return on equity, and dividend per share) as of the end of 2018 and 2019. The final sample for our baseline analysis consists of a panel of 123 non-financial European firms, of which 99 are in the core and 24 in the periphery, and their sovereigns. The top-100 firms by market capitalization are listed in Appendix Table A.1. We also collect data on 43 financial firms, which we use for benchmark purposes in section 3.2.

\footnotetext{
${ }^{2}$ Hull (2003) and Duffie and Singleton (2012) are standard textbook references in the literature on credit risk. Determinants and decomposition of sovereign and corporate CDS are discussed, respectively, in Longstaff et al. (2011) and Berndt and Obreja (2010). For an appraisal of the literature, see Augustin et al. (2014).

${ }^{3}$ We only consider firms with at least 300 valid (i.e., not stale) CDS quotes. Two European countries, Ireland and Austria, are omitted as they have only one non-financial firm on Markit with valid CDS data.

${ }^{4}$ This aspect is confirmed by the results in Table 5 of Augustin et al. (2021), where the effect on sovereign CDS of the interaction between COVID-19 and fiscal space is largely attenuated when including the foreign exchange rate returns for a sample of 13 countries outside the Eurozone.

${ }^{5}$ Berndt et al. (2007) point out that the cheapest to deliver option is less of a concern in contracts issued under the MMR clause compared to the full restructuring clause. Using corporate MMR spreads as dependent variable, the effect of full restructuring sovereign CDS, whose cheapest to deliver option is relatively less expensive, is likely to be underestimated, as our Table 4 shows.
} 
Summary statistics of the spreads over the period are reported in Panel A of Table 1, with countries grouped into core and periphery. For the former, France and Germany have the highest number of firms (40 and 33, respectively), while Italy and Spain are the most represented in the periphery (11 and 9, respectively). ${ }^{6}$ As expected, spreads on sovereign debt of core countries have been on average much lower than for peripherals (13 vs. 98 bps, respectively). For both groups, the period has been characterized by substantial fluctuations in the pricing of sovereign credit risk, as testified by the large standard deviations. Interestingly, unlike for sovereigns, the average CDS spreads of corporations in the core over the period is quite closely aligned to that of peripheral corporations (112 vs. 133 bps), and more volatile over time and in the cross section (205 vs. 119 bps). Panel B reports means and standard deviations of firm characteristics that capture relevant dimensions of credit risk. Peripheral firms are on average somewhat smaller and more leveraged than core firms. In our empirical analyses, we make sure our results are not unduly influenced by imbalances in the number of firms and their characteristics across regions by using, respectively, a re-sampling procedure and an entropy-balanced estimator.

Figure 1 presents a graphical illustration of the spreads over the study period. For each country, we plot a corporate CDS index computed as the average CDS spread across firms weighted by market capitalization as of the end of 2019. Spreads were mostly flat to slightly decreasing until the end of February, 2020. The onset of the pandemic is marked by a spike in CDS referencing non-financial companies across all countries, with average spreads exceeding 200 bps for Greek and Italian firms, followed by a reversal. By the end of the sample period, nearly all series are some 20 to $30 \mathrm{bps}$ above their pre-COVID levels. Consistent with the summary statistics, we note that corporate credit risk of firms in some core countries has been on average comparable and at times higher than that of peripheral companies (not controlling for characteristics). Figure 2 displays the time series of the CDS spreads on European sovereign debt. There, we again observe a run-up in spreads until June 2020 and a flattening thereafter. Compared to the corporate sector, there is a distinct fragmentation in the sovereign CDS market, with higher credit risk for peripheral

${ }^{6}$ These numbers are comparable to those in Berndt and Obreja (2010) and Bedendo and Colla (2015), considering that we filter out financial companies. 
countries.

Following Pagano et al. (2020), and spurred by the evidence in the previous figures, we date the beginning of the COVID-19 subsample as February 24, 2020, which corresponds to the first Italian lockdown. $^{7}$

To complete the picture of core/periphery classification, we display in Appendix Figure A.1 proxies for the fiscal space of the countries in our sample. Fiscal space can be broadly defined as the ability of a government to fund its fiscal policy and service its financial obligations (Romer and Romer, 2018). Following Augustin et al. (2021), we account for the multifaceted nature of fiscal space through a battery of variables capturing the amount of outstanding debt, the cost of financing,

and the overall quality of the government. Specifically, we report data as of December 2019 on gross government debt as a portion of GDP, interest expenditures on debt, and four indicators of institutional quality. ${ }^{8}$ All variables clearly confirm the presence of two clusters in the Euro Area, with the five countries in the core being less fiscally constrained than those in the periphery.

Lastly, we carry out a principal component analysis of CDS spreads (see Berndt and Obreja, 2010; Longstaff et al., 2011, for similar applications) before and after the coronavirus outbreak. Overall, the analysis shows that the COVID-19 shock increased the importance of the first factor for both corporations and especially sovereigns, as well as its loading on core countries. We defer a detailed discussion to Appendix A.

\subsection{Research hypotheses}

Our focus is on the sensitivity of corporate credit risk to that of its sovereign, which we term “corporate-sovereign nexus" or simply "nexus." In our empirical design, we measure the nexus with the slope coefficient in regressing corporate CDS spread changes onto those of the corresponding sovereign while controlling for aggregate and firm-level fundamentals, including the firm's equity return.

\footnotetext{
${ }^{7}$ Moving our event date to February 20, 2020 - when the first case of COVID-19 was diagnosed in the Italian town of Codogno - does not, however, affect our conclusions.

${ }^{8}$ The sources are the OECD, ECB, and World Bank.
} 
The COVID-19 pandemic offers a fruitful context to study how the nexus varies in a cross section of countries with different fiscal capacities at the inception of the shock. In normal times, the corporate-sovereign sensitivity could be influenced by a wealth of channels that are unrelated to a country's fiscal space. However, the occurrence of a large negative contraction triggering a surge in credit risk (a "disaster") with no immediate changes in fiscal capacity allows for a clean measurement of the amplifying role, if any, of ex-ante public finances on the nexus. Our identifying assumption is that the COVID-19 outbreak is exogenous to the pre-existing structure of the nexus and the level of fiscal capacity and generated a repricing of credit risk in the entire Eurozone as soon as news about the pandemic reached the market.

Our null hypothesis is that fiscal capacity does not shape the nexus in the face of a disaster. In other words, any comovement between corporate and sovereign credit risk results from exposure to common factors that are orthogonal to country-level fiscal space. This being the case, in the face of COVID-19 there should not be a differential reaction in the nexus between core and periphery

Hypothesis 0: In the aftermath of the COVID-19 pandemic, fiscal space is not a determinant of the corporate-sovereign nexus.

Alternatively, the literature offers two possible explanations for the link between corporate and government credit risk, which relate to the threat of higher taxes and the broad amplification of a negative shock, as opposed to the pricing of bailouts.

On the one hand, one might expect the transmission of an aggregate shock to demand to be amplified in countries with already high levels of sovereign credit spreads and limited fiscal space. For these countries, a further deterioration in government credit merit would increase credit spreads on the debt of domestic corporations through, for example, the threat of tax hikes and disruptive strikes, as in the model of Corsetti et al. (2013). The hazard of an increase in tax burden or expropriation is usually associated with the concept of "sovereign ceiling," a transfer from sovereign to corporate risk (Almeida et al., 2017). In a similar vein, Lee et al. (2016) view transmissions of 
sovereign risk to private sector firms as originating in the threat of expropriation and the transfer of country risks, like corruption and political instability. In this view, the shock would lead to a strengthening of the relation between corporate and sovereign credit risk that is more pronounced for risky governments. In our context, the argument that sovereign funding strains exacerbate the severity of the shock and private sector creditworthiness thus predicts that credit risk spillovers in the face of the pandemic should be felt more strongly in EU countries that are closer to their fiscal capacity limits.

Hypothesis A1: According to the "sovereign risk channel," the effect of the COVID-19 outbreak on the corporate-sovereign nexus should be stronger in the periphery of the EU.

On the other hand, a link between sovereign and corporate credit risk might arise from the pricing of government guarantees. Kelly et al. (2016) document that a collective government guarantee for the financial sector was priced in crash insurance contracts during the 2007-2009 Crisis. In a similar vein, Acharya et al. (2014) show that, during the European sovereign debt crisis, government bailouts increased the comovement between sovereign and domestic banks' CDS. For banks, credit risk comovement arises from two channels: (i) banks' holding of domestic sovereign bonds, and (ii) a backstop option offered by the government to domestic firms. In our framework, the first channel is not present, since non-financial firms do not retain significant amounts of sovereign bonds. However, if market participants perceive that a backstop option will be extended also to non-financial firms, changes in government risk would impact spreads of non-financial corporations through their effect on the value of guarantees. It is conceivable that, in the face of a large shock such as COVID-19, the government will use at least part of its fiscal space to rescue the non-financial corporate sector. The "bailout channel" thus predicts that COVID-19 should have strengthened the corporate-sovereign nexus in countries that were perceived to better sustain firms with ample and credible budgetary measures. 
Hypothesis A2: According to the "bailout channel," the effect of the COVID-19 outbreak on the corporate-sovereign nexus should be stronger in the core of the EU.

Both A1 and A2 predict that a firm's credit risk sensitivity to its own sovereign should become stronger overall in the face of COVID-19. However, they differ in their predictions regarding the role of fiscal space as captured by the core/periphery classification, with A1 implying that the nexus should increase more in the periphery, while A2 sees the nexus increasing in the core of the Union. ${ }^{9}$

In our empirical design, we are careful to rule out other channels than fiscal space that could trigger COVID-induced cross-sectional changes in the nexus, thereby marring our inference. For example, it could be the case that credit risk in peripheral countries was more impacted by the pandemic due to their industrial structure or firm financing constraints. We thus corroborate our conclusions by enriching our specification with country characteristics - measuring, for example, the severity of the pandemic and degree of country openness to international trade - and firm characteristics capturing profitability, liquidity, and reliance on the banking system.

\section{The corporate-sovereign nexus}

This section presents our main empirical results. In Section 3.1, we document how the sensitivity of corporate to sovereign credit risk changed as a result of the pandemic for core versus peripheral EU countries. In Section 3.2, we estimate the model separately by country and industry. In Section 3.3, we provide a number of analyses to assess the robustness of our findings along several dimensions and address the importance of a wealth of alternative economic channels.

\footnotetext{
${ }^{9}$ The competing hypotheses we test reflect two interpretations of security tracing back to J.S. Mill, who in Principles of Political Economy argues that "among the secondary causes which determine the productiveness of productive agents, the most important is Security. By security I mean the completeness of the protection which society affords to its members. This consists of protection by the government, and protection against the government."
} 


\subsection{Baseline results}

We test the alternative hypotheses outlined in section 2.2 within a panel regression model with corporate CDS spreads as the dependent variable. The setting allows us to exploit the granularity of the data and pin down the relation between corporate and government CDS spreads conditional on a number of aggregate and firm-level controls. In addition, and specific to the evolution of the COVID-19 shock, firm credit risk ultimately reacted to a government decision to impose national lockdowns halting, in part or in full, a number of corporate activities, so it is natural to think of the former as the outcome variable. Following Acharya et al. (2014) and Augustin et al. (2018), we work with daily growth rates in CDS; namely, first differences in log (sovereign and corporate) CDS spreads. This setup enhances the stationarity of the data, given that CDS are highly persistent on a daily basis, and is better suited for a panel of firms and countries with different levels of spreads. Therefore, we measure the nexus with the sensitivity (i.e., elasticity) of a firm's credit risk to that of its sovereign.

In our empirical approach, we seek to capture two dimensions of the corporate-sovereign nexus. First, in the time series, we interact all variables in the model with the dummy $E$ that equals one in the days after February 24, 2020 and zero otherwise. The interaction terms reveal how the COVID-19 shock changed pre-existing relations. Second, we look for differential effects in the cross section of countries by estimating the model separately for core versus periphery, which were characterized by markedly different fiscal capacity at the inception of the crisis (Augustin et al., 2021).

Our panel regression model takes the form

$$
\begin{aligned}
\Delta \log (\operatorname{CDS} \text { Corp })_{i j t}= & \alpha_{0}+\alpha_{1} \times E+\delta_{i}+\beta_{1} \Delta \log (\operatorname{CDS~Sov})_{j t}+\beta_{2} \Delta \log (\operatorname{CDS} \text { Sov })_{j t} \times E \\
& +\gamma_{1} X_{i j t}+\gamma_{2} X_{i j t} \times E+\varepsilon_{i j t}
\end{aligned}
$$

where $\Delta \log (\mathrm{CDS} \text { corp })_{i j t}$ is the first difference (between day $t$ and day $t-1$ ) in the $\log \operatorname{CDS}$ spread of company $i$ incorporated in country $j$, and $\Delta \log (\text { CDS Sov })_{j t}$ is the contemporaneous first 
difference in the $\log$ CDS spread on the sovereign debt of country $j$. The vector $X$ includes the following: a lag term $\Delta \log (\mathrm{CDS} \text { corp })_{i j t-1}$ to further filter residual persistence in the dependent variable; the firm equity return $R_{i j t}$, which mirrors the pricing of debt under standard Merton (1974)-type contingent-claim models and should be sufficient (absent guarantees) to absorb the effect of aggregate shocks on both firm's assets and sovereign creditworthiness that could bias our inference (Acharya et al., 2014); and the CBOE option implied volatility index $V I X_{t}$, which captures aggregate volatility and risk appetite (using VSTOXX as an alternative does not affect our results). All variables enter the equation both in level and interacted with the COVID-19 period dummy $E$. The firm fixed effects $\delta_{i}$ absorb away any time-invariant attributes such as country and sector, and arguably - given the relatively short time span of our event window - book leverage. ${ }^{10}$

Our focus is on $\beta_{2}$, which measures how the corporate-sovereign nexus changed during the COVID-19 subsample. The null hypothesis (Hypothesis 0) would predict a statistically insignificant difference in $\beta_{2}$ between core and periphery. A positive $\beta_{2}$ that is larger for peripheral than core countries would provide support to the sovereign risk channel (Hypothesis A1). By contrast, an estimate of $\beta_{2}$ that is larger for core countries would suggest that the pricing of government guarantees (Hypothesis A2) has led to a strengthening of the nexus in more creditworthy countries.

Columns (1) and (2) in Table 2 present the corresponding OLS estimates for core and periphery, respectively, with associated standard errors clustered at the firm level in parentheses. ${ }^{11}$ The first row of the table collects the estimates for $\beta_{1}$. In the period preceding the Italian lockdown, a shock to sovereign credit risk was accompanied by a statistically significant change in corporate risk in the same direction. The effect is about twice as large for non-financial corporations in the periphery, for which a $10 \%$ increase in sovereign CDS translates into a $2.08 \%$ increase in their CDS, compared to firms in the core, for which a shock of the same magnitude results in a more

\footnotetext{
${ }^{10}$ Market leverage wounld instead mostly be driven by changes in the value of equity, for which we already control. We also considered additional controls, such as Euroswap rates and the slope of the term structure of sovereign credit risk, and find they do not affect our conclusions. In section 3.3 , we show that our findings continue to hold using an alternative pooled model with fully saturated time and sector or country fixed effects.

${ }^{11}$ We resort to OLS estimation because the time dimension far exceeds the number of cross-sectional units, which makes the bias with respect to estimating a dynamic panel fairly negligible. In section 3.3, we show our results are robust to using a GMM dynamic panel data estimator.
} 
modest $1.27 \%$ increase. $^{12}$

The second row of the table reveals that the COVID-19 pandemic had a massive impact on the corporate-sovereign nexus for companies in the core, as demonstrated by an economically and statistically significant $\beta_{2}^{\text {Core }}$ coefficient. The 0.125 estimate implies that the sensitivity of these companies' credit spreads to shocks in their sovereigns effectively doubled during the period, bringing the overall impact $\left(\beta_{1}^{\text {Core }}+\beta_{2}^{\text {Core }}\right)$ to a level of about 0.25 - thus, a $10 \%$ increase in sovereign spreads in the second half of the sample translates into an expected $2.5 \%$ increase in spreads for corporate sector debt. Notably, this figure is at par with that of companies in the periphery, for which the additional contribution from the COVID-19 sample $\beta_{2}^{\text {Peri }}$ is a meager 0.052 (statistically insignificant). The $p$-value for the $F$-test of equality between $\beta_{2}^{\text {Core }}(0.125)$ and $\beta_{2}^{\text {Peri }}$ (0.052), reported in the last row of the table, confirms that their difference is not only economically but also statistically significant. Overall, these results lend strong support to Hypothesis A2; namely, the repricing of credit risk in the face of the shock led to a tighter corporate-sovereign relation in countries that were better positioned to extend government support.

Among the controls, we note some persistence in CDS growth rates, whose extent did not change in the COVID-19 sample. The loading on stock return is strong and negative and becomes larger in absolute terms during the pandemic for both core and periphery, in line with the intuition from the Merton (1974) model. Option-implied market volatility has a positive effect on spread changes in the first part of the sample for both groups and a large increase during the COVID-19 period, concentrated in core countries.

In columns (3) and (4) of Table 2 we perform a value-weighted least squares estimation, where weights are based on equity market capitalization (as of 2019). Intuitively, the larger the company, the stronger its ties with the government, according to both a bailout channel and a coercive taxation motive. This specification strengthens our conclusions, as the difference in the $\beta_{2}$ coefficient between core and periphery widens even further to a full 0.15 . This evidence is consistent with market participants perceiving and pricing in generous and effective government transfers mostly

${ }^{12}$ These estimates are comparable to, although generally higher than, those reported in Bedendo and Colla (2015), possibly because of additional risk transfer taking place during the European sovereign debt crisis, which is not in their sample. 
targeting larger firms in the core. In peripheral countries, with relatively weaker public finances and less resilient structural economic conditions, the COVID-19 shock was accompanied by a very modest increase in corporate-sovereign sensitivity.

In columns (5) and (6), we repeat our baseline analysis using the entropy-based reweighting algorithm of Hainmueller (2012); see Jacob et al. (2018) for a recent application. Given that sample selection is driven by CDS data availability, our estimates could be biased by structural differences in the characteristics of listed firms headquartered across the two Eurozone regions. To mitigate this concern, we rely on a reweighting scheme that matches the first three moments of credit risk related variables - market capitalization, leverage, market to book ratio, and equity volatility between core and periphery. ${ }^{13}$ The results show that accounting for covariate imbalance raises the difference between $\beta_{2}^{\text {Core }}$ and $\beta_{2}^{\text {Peri }}$, in both magnitude and statistical terms.

\subsection{Subsample analysis}

Panel A of Table 3 reports the loadings on sovereign CDS when the model in Eq.(1) is separately estimated by country (the controls are included, but their coefficients are omitted for brevity). Despite the substantial cross-country heterogeneity in the number of firms, we find that every country in the core is characterized by an economically large and statistically significant surge in sovereign credit risk transfer during the COVID-19 sample, with values ranging from 0.076 for Finland to 0.156 for Germany. In contrast, none of the peripheral members displays a significant reaction to the pandemic. This result confirms that our core/periphery classification has a strong financial backbone in the repricing of corporate credit risk induced by the shock.

In Panel B of Table 3 we stratify the data by four industrial sectors; namely, energy and utilities, industrial, technology, and goods and services. ${ }^{14}$ The effect we document is not concentrated in a single sector but rather pervasive, with $\beta_{2}$ coefficients ranging from 0.055 for tech firms to 0.120 for goods and services. Notably, the sectors for which we find a larger increase in comovement with the

\footnotetext{
${ }^{13}$ Entropy balancing optimally determines weights to achieve exact moment matching while keeping the distribution of observations as close as possible to the data in an entropy sense. Appendix Table A.2 reports the moments of credit risk related variables before and after the reweighting.

${ }^{14}$ The industry classification is based on Refinitiv Eikon.
} 
sovereign correspond to those classified by Dunn et al. (2020) as COVID-19 sensitive using credit card transaction data, which confirms their strong reliance on the pricing of government support. The last column of the panel provides estimates for financial firms, which are excluded from our working sample. The increase in the corporate-sovereign nexus for financials is lower than all other sectors and only marginally significant, despite being the highest before the pandemic. This result is again consistent with the non-financial nature of the shock and government guarantees of credit extended to the real sector.

\subsection{Robustness and alternative channels}

We assess the robustness of our findings to a number of econometric concerns and model design choices, and test for the relevance of alternative economic channels using either firm-level or country-level variables.

\section{Robustness analysis}

In columns (1) and (2) of Table 4, we augment the model with firm-level at-the-money optionimplied volatility. ${ }^{15}$ This variable provides us with a timely and forward-looking market assessment of a firm's total risk, which is naturally linked to default risk. Its inclusion actually widens the difference between the $\beta_{2}$ coefficient of core (which remains unchanged) and periphery (which is halved).

Next, we worry that our findings might be picking up the effect of the ECB's Pandemic Emergency Purchase Programme (PEPP), the temporary asset purchase program targeting private and public sector securities. While the program does not directly target CDS contracts, it might still act as a confounding factor by exerting downward pressure on bond yields with an intensity that depends on market size and thus overlap in part with the core/periphery classification. We thus repeat our analysis only on the sample of non-eligible PEPP corporate issuers and report the corresponding estimates in columns (3) and (4). ${ }^{16}$ We find that our main conclusions also extend to this

\footnotetext{
${ }^{15}$ The source is Bloomberg. Data are missing for seven core and four peripheral firms.

${ }^{16}$ The list of eligible PEPP collateral is available at https://www.ecb.europa.eu/paym/coll/assets/html/index.en. html.
} 
subset of the data, as the loading on sovereigns more than doubles for core countries during the COVID-19 sample, whereas that for companies in the periphery shows a modest and statistically insignificant increase. ${ }^{17}$

In columns (5) and (6), we re-estimate our baseline model while restricting the COVID-19 sample to only one trading month (i.e., through March 24, 2020). By doing so, we minimize concerns that our estimates are picking up the effect of direct government support to local demand, the foreseeable effects of the European Recovery Plan - the implementation of which was not even being discussed - and the extent of FED's intervention. If anything, this setup strengthens our conclusions.

Columns (7) and (8) of Table 4 show that relying on the Arellano-Bover/Blundell-Bond system GMM dynamic panel data estimator (Arellano and Bover, 1995; Blundell and Bond, 1998) as opposed to OLS reinforces our conclusions, as the difference in $\beta_{2}$ between core and periphery widens at 0.16 . Using a FGLS estimator as an alternative again confirms our findings. The results are also robust to using data aggregated at the weekly frequency (columns 9-10), selecting the cum-restructuring clause for corporate CDS (columns 11-12), and adding a squared equity term to account for non-linearities in the equity-CDS relation (see Appendix Table A.4).

Finally, we conduct two analyses to further account for differences in characteristics between the two groups. First, we carry out the following bootstrap re-sampling experiment. In every bootstrap run, we match each firm in the periphery with a random core firm in the same industry classification. We then estimate our baseline panel regression on this randomized sample of core firms, whose size and industrial composition match (by design) those in the periphery, store the resulting coefficients and standard errors, and repeat the procedure 1,000 times. Figure 3 plots the distributions of the $\beta_{2}$ coefficient (left panels) and its $t$-statistic (right panels) for the equally-weighted (top panels) and market cap-weighted (bottom panels) models across the 1,000 randomized core samples. As we can see, none of these artificial samples delivers estimates that are lower than those obtained in Table 2 for the actual periphery (which are marked in each panel by a vertical

${ }^{17}$ This result lines up with evidence from Krishnamurthy and Vissing-Jorgensen (2011) that QE has a significant effect on CDS spreads of low-rated securities only, while our sample is composed of high-rated issuers. 
dotted line). We conclude that our analysis is not biased by differences in the number of firms or industrial composition between core and periphery.

Second, we restrict the estimation to the subsample of firms whose average CDS during the pre-COVID period was higher than that of their government. The corresponding estimate for $\beta_{2}$ remains unchanged at 0.125 for core countries and only marginally changes to 0.050 in the periphery. Our result is therefore not triggered by asymmetries in the effect of changes in sovereign risk on firms below or above its credit merit (Almeida et al., 2017). In a similar vein, we stratify the sample by the extent of government ownership, defined as the fraction of a firm's equity that is owned by the government and sovereign wealth funds (source: Bloomberg). Our conclusions continue to hold irrespective of whether we work on companies whose government ownership falls either below or above the cross-sectional average. ${ }^{18}$ Moreover, when added to the regression, the interaction term between government ownership and sovereign CDS is largely statistically insignificant. We thus reckon that the effect we document is not merely a reflection of direct government holdings.

\section{Alternative channels: Firm-level characteristics}

We verify that sovereign CDS spreads are not proxying for firm-level characteristics that capture a company's sensitivity to the COVID-19 shock and correlate with sovereign credit risk. We include these variables in level in the baseline specification and also allow for an interaction effect with $\Delta \log (\mathrm{CDS} \text { sovereign })_{j t}$. The corresponding estimates are collected in Table 5, where $Z$ alternatively denotes three different firm-level characteristics, that are all computed in excess of the year-industry median.

Wenzhi et al. (2021) show that the pandemic-induced drop in stock prices was milder among firms with larger pre-2020 profitability. We thus consider in columns (1) and (2) a firm's profit before taxes over employees $(P P E) .{ }^{19}$ Fahlenbrach et al. (2020) provide evidence that firms with

\footnotetext{
${ }^{18}$ Specifically: for below-average firms, $\beta_{2}^{\text {Core }}=0.122$ with $t$-stat of 6.8 vs $\beta_{2}^{\text {Peri }}=0.072$ with $t$-stat of 1.6 ; for above-average firms, $\beta_{2}^{\text {Core }}=0.134$ with $t$-stat of 4.3 vs $\beta_{2}^{\text {Peri }}=0.026$ with $t$-stat of 0.6 .

${ }^{19}$ We obtain analogous results using either profits before taxes or net asset turnover (not shown for brevity).
} 
greater financial flexibility exhibited stronger resiliency to COVID-19 thanks to their ability to fund the revenue shortfall resulting from the shock and, as a consequence, were less in need of policy responses. We control for this feature by adding Liquidity, the ratio of current assets minus stocks to current liabilities, in columns (3) and (4) of the table. Relatedly, a firm's funding structure and reliance on the banking sector affect its ability to cope with unexpected shortfalls in profitability by temporarily increasing borrowing. Acharya and Steffen (2020) show that firms' ex-ante funding structure is priced in the cross section of stock returns. In columns (5) and (6), we capture this effect through Loans, the log of a firm's ratio of short-term financial debt to total debt.

The overall message from Table 5 is that none of profitability, liquidity, or bank dependence explains the different increases in the intensity of the corporate-sovereign nexus in the two regions. In other words, unlike in the periphery, we continue to find a strengthening of the relation between corporate and sovereign credit risk in the core of the Eurozone.

\section{Alternative channels: Country-level characteristics}

We further explore the relevance of alternative explanations to fiscal slackness using countrylevel proxies for the severity of the COVID-19 shock on the country's productive system. Our empirical setup and variable selection is guided by Augustin et al. (2021). Following their approach, we report in column 1 of Table 6 results from a pooled (i.e., difference-in-difference) panel version of Eq.(1), where firm-level data are pooled across all countries while allowing for a differential loading on sovereign risk in core countries. The coefficient on the triple interaction term - Core $_{i} \times \Delta \log (\mathrm{CDS} \text { sovereign })_{j t} \times E-$ in the second row of the table confirms that the corporate-sovereign nexus in core countries $\left(\right.$ Core $\left._{i}=1\right)$ during COVID-19 $(E=1)$ is larger by 0.113 than that in peripheral countries.

Given that national lockdowns caused a severe slowdown or even halt in international trade, we control in column (2) for a country's degree of openness (computed as the ratio of exports plus imports to GDP), which measures its reliance on foreign demand and the international supply chain 
(Ramelli and Wagner, 2020). ${ }^{20}$ In column (3), we consider the country's share of GDP generated by tourism, as this sector was arguably among the most impacted by the shock, and in turn generated a slowdown in satellite activities. In column (4), we control for the strength of a country's healthcare system, which we measure with the number of hospital beds per thousand inhabitants, as better-positioned systems likely attenuated or deferred the social and economic consequences of the pandemic. Finally, while all countries we examine responded to the COVID-19 shock by imposing similar economic freezes during the sample period, in column (5) we explicitly account for the strictness of government-imposed "lockdown-style" policies through the Oxford COVID19 Government Response Tracker. ${ }^{21}$ As an alternative modelling approach, we consider a fully saturated fixed effect model by adding week times sector (in column 6) and week times country (in column 7) fixed effects, in addition to firm fixed effects.

All models in Table 6 leave our conclusions unchanged: During the COVID-19 period, countries in the core exhibit a strengthening in the sensitivity of corporate to sovereign credit risk, unlike peripheral countries, for which the effect was muted.

\subsection{Deviations from fundamental credit risk}

Standard models for credit risk predict that in a frictionless world, any shock to a firm's asset would affect its liabilities, with an intensity that depends on leverage. By contrast, we find that in the face of COVID-19, the cost of default risk protection for non-financial corporate debt became more tightly linked to sovereign credit risk, even after controlling for, among other variables, equity returns. This evidence is consistent with the pricing of government guarantees benefitting debtholders, which creates a wedge in the valuation of corporate claims. We gain further support for this argument by following the approach in Kelly et al. (2016), who document systematic deviations of actual spreads from those predicted by a standard structural model of default as a function of size during the Global Financial Crisis. They argue that this fact reflects the pricing of

\footnotetext{
${ }^{20}$ Data on a firm's reliance on international markets - e.g., the ratio of foreign to domestic revenues or sales - are insufficiently populated in Refinitiv Eikon for us to carry out this analysis at the firm level.

${ }^{21}$ This variable is available on a daily basis. The previous three variables, by contrast, are available at an annual frequency, and we use their values as of the most recent year end preceding date $t$ to prevent any look-ahead bias.
} 
bailout guarantees in the financial sector. ${ }^{22}$ We show that a similar analysis on our sample uncovers deviations that become wider for large firms during COVID-19 in core countries only.

We compute the model-implied CDS rate from the Merton (1974) model using Bharath and Shumway (2008)'s measure of distance to default (DD). ${ }^{23}$ Similar to Kelly et al. (2016), we then estimate cross-sectional weekly regressions of the form

$$
\mathrm{CDS}_{i t}=a_{t}+b_{1 t} \text { Merton Spread }_{i t}+b_{2 t} \text { Size }_{i t}+b_{3 t} \text { Leverage }_{i t}+\varepsilon_{i t}
$$

separately for observations in the core and periphery. As in Kelly et al. (2016), we define size as the one-month-lagged log of market value of equity plus book value of debt and leverage as the one-month-lagged log ratio of book value of assets to market value of equity.

Figure 4 plots the four-week trailing average of the resulting slope coefficient on size $\left(b_{2 t}\right)$, along with standard error bands. Controlling for leverage and volatility, the slope of risk-adjusted corporate spreads to firm size in the pre-COVID sample fluctuates in a rather narrow and similar range in both core and peripheral countries. As the shock hits the markets, we observe markedly different behaviors between the two areas. The slope becomes more negative in core countries, and the discount widens to values as much as five times pre-COVID levels. Despite the similarity in the severity of the shock and the relative increase in credit risk, size does not systematically explain departures from fundamentals for CDS referencing firms in peripheral countries. Therefore, at the outbreak of the COVID-19 shock, actual CDS spreads were priced at a discount with respect to predicted spreads only in the case of large(r) companies located in core EU countries; in other words, countries that were perceived to be far from their fiscal capacity limits and whose governments were deemed ready to extend bailout guarantees.

\footnotetext{
${ }^{22}$ This type of analysis is compliant with the approach in Bai et al. (2019), who argue that the basket-index put spreads puzzle can be solved by accounting for equity dynamics and the "leverage effect."

${ }^{23}$ As is customary, we take current liabilities plus one half of long term debt to proxy for face value of debt and close price times amount of ordinary shares as market value of equity. We update the stock's volatility using the RiskMetrics variance model to take into account time variation in risk. Using option-implied volatility diminishes sample size due to data availability but conveys the same message.
} 


\section{Disaster-risk intensity-based model with bailout guarantees}

To rationalize the evidence in the previous section, we develop an asset pricing model featuring both disaster risk and government bailout. The scope of this analytical framework is twofold. First, it helps us understand how fiscal space (via the pricing of government guarantees) enters the relation between corporate and sovereign credit risk in the face of a disaster. Second, it allows us to develop further relations that we explore in the data.

In the model, a disaster triggers a negative jump in consumption and an increase in corporate credit risk through a jump in the default intensity of non-financial corporations. The government can provide collective guarantees through a ceiling on the size of the jump, thereby limiting the increase in the level of credit spreads. However, when the guarantee is activated, it causes an increase in the default risk of public debt that is commensurate with the portion of the shock that the government has absorbed. This mechanism is responsible for the comovement between corporate and sovereign credit risk conditional on the disaster taking place.

\subsection{Model setup}

The model builds on the disaster-risk bailout-augmented setup of Kelly et al. (2016) and Gandhi et al. (2020). We assume that a disaster of stochastic intensity hits the economy with probability $p_{i} \sim \Pi$, a persistent Markov process with $i \in\{1, . ., I\}$ states. All stochastic processes are specified under the risk-neutral measure $\mathbb{Q}$. In the face of a rare disaster, the growth rate in log aggregate (i.e., "world") consumption $\Delta \mathcal{C}_{t+1}$ jumps by the Gaussian process $J_{t}^{r}$, with $\mathbb{E}_{t}\left[J_{t+1}^{r}\right]=\theta_{r}$. The process for $\Delta \mathcal{C}_{t+1}$ is modelled as the mixed jump-diffusion

$$
\Delta \mathcal{C}_{t+1}= \begin{cases}\gamma_{i}-\sigma_{i} \eta_{t+1} & \text { No Disaster } \\ \gamma_{i}-\sigma_{i} \eta_{t+1}-J_{t+1}^{r}, & \text { Disaster }\end{cases}
$$

where $\gamma_{i}$ and $\sigma_{i}$ denote the state-dependent mean and volatility, respectively, and $\eta_{t+1}$ is a standard normal innovation. 
We are interested in the implications of the disaster for the pricing of default risk. As is customary in the credit risk literature (see, among others, Longstaff et al., 2005), we model the default event as the first jump of a Poisson process with state-dependent intensity. We assume that the disaster triggers a jump $J_{t}^{\lambda}$ in the risk-adjusted intensity of default that is normally distributed and perfectly correlated with the jump in consumption growth $J_{t}^{r}$, with $\mathbb{E}_{t}\left[J_{t+1}^{\lambda}\right]=\theta_{\lambda}$ and $\mathbb{V}_{t}\left[J_{t+1}^{\lambda}\right]=\delta_{\lambda}^{2}$. In this way, times of low consumption growth (and higher marginal utility) are associated with higher risk-adjusted spreads. The relation between $J_{t}^{\lambda}$ and the jump in the risk-adjusted default intensity of the average corporation $J_{t}^{c}$ depends on government intervention.

Specifically, we assume that the risk-adjusted distribution of firm $c$ 's default intensity $\lambda_{t}^{c}$ evolves according to ${ }^{24}$

$$
\lambda_{t}^{c}= \begin{cases}\nu^{c}+\phi_{c} \sigma_{i} \eta_{t}+\sigma_{c} \epsilon_{t} & \text { No Disaster } \\ \nu^{c}+\phi_{c} \sigma_{i} \eta_{t}+\sigma_{c} \epsilon_{t}+\kappa_{c} J_{t}^{c} . & \text { Disaster }\end{cases}
$$

In the ex-disaster region, the parameter $\nu^{c}$ captures the unconditional intensity while $\phi_{c}$ is the firm-specific sensitivity to aggregate consumption growth innovations. The firm is also exposed to an idiosyncratic innovation $\epsilon_{t}$ in credit risk. In the disaster state, a government stands ready to bail out its corporate sector should the realization of $J_{t}^{\lambda}$ be deemed too large. We capture government intervention through the fiscal policy function

$$
J_{t}^{c}=\min \left\{J_{t}^{\lambda}, \underline{J}\right\}
$$

This specification implies that the actual jump in corporate credit risk $J_{t}^{c}$ is bounded from above by the amount of the (deterministic) guarantee $\underline{J}$. If an excessively severe disaster hits the economy - that is, if $J_{t}^{\lambda}$ is too large - state intervention mitigates the increase in corporate $\mathbb{Q}$ default intensity. Stronger guarantees map into lower $\underline{J}$. Note that $\underline{J}$ does not correspond to the sheer amount of government support (i.e., a fiscal package or direct transfers) to firms. Rather, it captures how government spending factors into the pricing of credit risk claims. Therefore, it incorporates the market participants' assessment of how credibly the government can sustain its

${ }^{24}$ Alternatively, one could view $c$ as the aggregation of the domestic private sector. 
spending through an efficient use of resources and promote a swift recovery. ${ }^{25}$

Finally, the parameter $\kappa_{c}$ captures firm c's sensitivity to the actual contraction, so that its $\lambda_{t}^{c}$ is effectively shocked by an amount $\kappa_{c} J_{t}^{c}$. The cross-sectional mean (across all firms in the "world") of $\kappa_{c}$ is one. Therefore, government intervention ultimately affects the pricing of firm-level credit risk through two parameters: the country-specific shock $\underline{J}$ and the firm-level multiplier $\kappa_{c}{ }^{26}$

Taking the first difference of Eq. (4) yields a discrete-time Ornstein-Uhlenbeck process, in the spirit of Lando (2009). Defining $\mu_{t}^{c}=\nu^{c}-\lambda_{t}^{c}$, the process for changes in default intensity $\Delta \lambda_{t+1}^{c}$ satisfies

$$
\Delta \lambda_{t+1}^{c}= \begin{cases}\mu_{t}^{c}+\phi_{c} \sigma_{i} \eta_{t+1}+\sigma_{c} \varepsilon_{t+1} & \text { No Disaster } \\ \mu_{t}^{c}+\phi_{c} \sigma_{i} \eta_{t+1}+\sigma_{c} \varepsilon_{t+1}+\kappa_{c} J_{t+1}^{c} . & \text { Disaster }\end{cases}
$$

Unlike previous studies, we explicitly model the relation between a government's credit quality and the magnitude of its "put option" (Veronesi and Zingales, 2010). To be precise, we assume that the sovereign debt default intensity $\lambda_{t}^{g}$ is also state-dependent and that its jump in the face of the disaster equals the support it pledges to its corporate sector

$$
\Delta \lambda_{t+1}^{g}= \begin{cases}\mu_{t}^{g}+\phi_{g} \sigma_{i} \eta_{t+1} & \text { No Disaster } \\ \mu_{t}^{g}+\phi_{g} \sigma_{i} \eta_{t+1}+\max \left\{J_{t+1}^{\lambda}-\underline{J}, 0\right\} . & \text { Disaster }\end{cases}
$$

Changes in default intensity in public debt have drift $\mu_{t}^{g}=\nu^{g}-\lambda_{t}^{g}$ and loading $\phi_{g}$ on aggregate consumption growth innovations. The portion of the jump that is absorbed by the government generates an increase in default risk of its debt, which is therefore jointly determined by the realized disaster $J_{t+1}^{\lambda}$ and the size of the guarantees $\underline{J}$. Appendix Figure A.3 provides a graphical illustration of the government bailout policy implied by the model. ${ }^{27}$

\footnotetext{
${ }^{25}$ In this sense, we expand the discussion in Romer and Romer (2018), where the size of the fiscal stimulus depends on fiscal space, by arguing that the macroeconomic conditions characterizing a country at the beginning of a crisis determine market expectations of the effectiveness of its fiscal package.

${ }^{26}$ Our framework shares similarities with Mäkinen et al. (2020), where government support is measured by two parameters capturing the strength of the guarantee and its riskiness. Unlike their agency model, we allow one parameter to capture the consequences for asset prices of government intervention, essentially triggered with certainty by a large disaster.

${ }^{27}$ For parsimony, we do not allow for an idiosyncratic component to public debt, akin to the expression for corporate credit risk. Introducing such an element, however, would not affect any of the results. On a related matter, our conclusions extend to allowing a sensitivity $\kappa_{g}$ of government credit spreads to the cost of fiscal intervention, from which we abstract for simplicity. Moreover, we do not model the direct increase in sovereign credit risk resulting from a disaster, such as reduced tax revenues which may impair government's ability to repay pre-disaster debt. Rather, we assume that all consequences for the public sector are either absorbed by the ex-disaster component or come from bailout-financing debt.
} 


\subsection{Model-implied corporate-sovereign nexus}

Our framework allows us to explicitly express the relation between changes in corporate and sovereign credit risk as a function of the structural parameters. As a first step, since we empirically measure credit risk with CDS spreads, we establish a mapping between spreads and default intensities.

Proposition 1. Assume constant risk-adjusted recovery rate $R$. Spread changes are approximately equal to the product of first differences in risk-adjusted default intensities and losses given default.

$$
\Delta \mathrm{CDS}_{t+1} \approx(1-R) \Delta \lambda_{t+1}
$$

Proof. See Appendix B.

Next, let $\Phi$ be the CDF of a normal random variable evaluated at the point $\frac{J-\theta_{\lambda}}{\delta_{\lambda}}$ and $\varphi$ its corresponding pdf. The covariance between changes in government and corporate CDS spreads can be expressed in closed form as follows.

Proposition 2. Conditionally on the fiscal policy function,

$$
\operatorname{Cov}\left(\Delta C D S_{t+1}^{c}, \Delta C D S_{t+1}^{g}\right) \approx \underbrace{\phi_{g} \phi_{c} \sigma_{i}^{2}}_{\begin{array}{c}
\text { Ex-disaster } \\
\text { Term }
\end{array}}+\underbrace{p_{i} \kappa_{c} \mathbb{E}_{t}\left[\max \left\{J_{t+1}^{\lambda}-\underline{J}, 0\right\}\right]\left(\underline{J}-p_{i} \min \left\{J_{t}^{\lambda}, \underline{J}\right\}\right)}_{\text {Disaster Risk Term }} .
$$

Proof. See Appendix C.

Eq. (8) clarifies that the corporate-sovereign covariance can be decomposed into two terms. The first term captures the link between corporate and sovereign credit risk that arises from common exposure to ex-disaster aggregate economic shocks. As long as the probability $p_{i}$ that a disaster hits the economy and the government needs to intervene to support corporations is low to negligible, this term dominates the covariance. As soon as market participants observe sights of a tail event and start factoring in a higher probability of disaster, the relative contribution of the 
second term takes up. ${ }^{28}$ This "disaster risk term" is increasing in the probability of the occurrence of a disaster $p_{i}$, the corporate sensitivities to disaster risk $\kappa_{c}$, and the product of expected jumps in firm and government credit risks.

From Eq. (8), we see that higher corporate sensitivities $\kappa_{c}$ always map into higher corporatesovereign covariances. The effect of an increase in $\underline{J}$, by contrast, is not as obvious, as $\underline{J}$ enters the expression in a nonlinear way. However, taking the derivative of Eq. (8) with respect to $\underline{J}$ yields the following result.

Corollary 1. Assuming for simplicity $\delta_{\lambda}=1$ and provided $\underline{J}>.5\left(\theta_{\lambda}+\frac{\phi}{1-\Phi}\right)$, the corporatesovereign nexus decreases in the ceiling to the default intensity of domestic corporations $\underline{J}$

$$
\frac{\partial \operatorname{Cov}\left(\Delta C D S_{t+1}^{c}, \Delta C D S_{t+1}^{g}\right)}{\partial \underline{J}}<0,
$$

or, if we define Guarantee as $-\underline{J}$,

$$
\frac{\partial \operatorname{Cov}\left(\Delta C D S_{t+1}^{c}, \Delta C D S_{t+1}^{g}\right)}{\partial G \text { Garantee }}>0 .
$$

Appendix $\mathrm{C}$ contains derivations. Under the parameter restriction that the government does not assume a disproportionate amount of corporate risk, the covariance between sovereign and corporate CSD spreads increases with the extent of bailout guarantees, in the spirit of Acharya et al. (2014). An implication of Corollary 1 is that governments with wider fiscal space, whose bailout guarantees are considered larger and more effective, should display a stronger increase in the link between private and public sector credit risk as the disaster hits, holding all other parameters fixed.

\footnotetext{
${ }^{28}$ To clarify, let the system begin in the state where the probability of a disaster occurring is the lowest. The system stochastically transits to a state featuring a higher possibility of a catastrophe, which eventually occurs. As long as the process sojourns in a state with relatively high $p_{i}$, a disaster is likely to occur, even after a jump - for instance, a lockdown following an outbreak or another pandemic wave. As in Krishnamurthy and $\mathrm{Li}$ (2020), a large economic contraction induces market participants to update their inference about the Markov state. This feature allows the one-time occurrence of a disaster to generate long-lasting repricing of tail risk and associated bailouts.
} 


\subsection{Model predictions and empirical analysis}

The model-implied relation we establish in the previous section enables us to gain a structural interpretation of the empirical facts we document in Section 3. For the sake of our discussion, let the "world" be divided into two groups of countries $j=\{$ Core, Peri $\}$. The two groups differ in the extent of perceived government support and in the reliance of both their sovereign and (average) corporate debt default intensities on consumption shocks.

The first row of Table 2 reports that the sensitivity of corporate to sovereign risk was positive and higher for firms in the periphery during the pre-COVID sample, when pandemic disaster was by and large unpriced. From Eq. (8), this finding implies that the ex-disaster term is larger in the periphery, possibly because of a more pronounced sensitivity of sovereign credit risk to ex-disaster fluctuations.

As soon as the first signs of the pandemic reached the market, the investors revised the likelihood of a disaster and priced in the value of government bailout of the private non-financial sector. The second row of Table 2 reveals a positive and significant increase in the corporate-sovereign nexus for core countries only in the aftermath of COVID-19. This indicates that a radical repricing of disaster risk reshaped the relation in credit markets. Turning again to Eq.(8), this result must originate from differences between core and periphery in the effectiveness of the government backstop option and in the (average) corporate sensitivity to bailout. ${ }^{29}$ The wider fiscal space of core countries implies that guarantees were likely perceived to be stronger for core firms, or $\underline{J}^{\text {Core }}<\underline{J}^{\text {Peri }}$. The difference in average corporate sensitivities $\kappa_{c}^{\text {Core }}$ and $\kappa_{c}^{\text {Peri }}$ could be either positive or negative and thus either amplify or attenuate differences in the strength of guarantees.

To infer the direction and contribution of the two components - amount of bailout and firm sensitivity to government intervention - on the corporate-sovereign credit risk comovement, we resort to the synthetic control method of Abadie et al. (2010); see Almeida et al. (2017) for a recent application. In our setup, the rationale for the method is as follows. Let the treatment

\footnotetext{
${ }^{29}$ The covariance term in Eq. (8) is indeed only the numerator of the $\beta_{2}$ coefficient measuring the corporate-sovereign nexus. We verify that the variance-comparison Levene's test cannot reject the null hypothesis of equality between groups of growth rates of sovereign spreads ( $p$-value: 0.12 ) and conclude that differences between $\beta_{2}^{\text {Core }}$ and $\beta_{2}^{\text {Peri }}$ truly arise from the covariance between corporate and sovereign spread changes.
} 
be the simultaneous occurrence of a jump in consumption growth during COVID-19 and bailout guarantees equal to government support in a given EU area $j$ - in other words, the treatment is the event $\left(\mathbb{1}_{[E=1]} \times \mathbb{1}_{\left[\underline{J}=\underline{J}^{j}\right]}\right)$. The outcome variable is corporate CDS spread with five years tenor. The synthetic control method permits us to infer the unobservable counterfactual CDS spread of a company headquartered in area $j$ had it been exposed to the same shock but priced according to bailout guarantees in the other EU area, all else being equal - that is, we want to compute the CDS under $\left(\mathbb{1}_{[E=1]} \times \mathbb{1}_{\left[\underline{J}^{\prime} \underline{J}^{-j}\right]}\right)$.

We collect details on the implementation of the method in Appendix D and provide an example to clarify matters. Consider the German company E.ON SE. We would like to observe its CDS spreads if it were in the periphery and COVID-19 hits, so that the firm would have been deemed to receive less effective government support than it had in the core. We can approximate the potential outcome by choosing, from the convex hull of CDS on peripheral firms, a portfolio of firms with similar values of a set of outcome predictors - for instance, such firms could include Enel S.p.A. and Atlantia S.p.A. In our application, we use as predictors the following variables capturing relevant dimensions of corporate credit risk: five-year credit rating, historical market beta and volatility, quintiles by market capitalization, share price over book value per share, and total debt over total capital.

The procedure provides us with two time series of CDS quotes: a "synthetic core" series, which reproduces the hypothetical CDS of core firms had they been headquartered in the periphery, computed as weighted averages of portfolios of suitable peripheral CDS, and symmetrically, a "synthetic periphery" series that tracks the hypothetical CDS of peripheral firms had they been incorporated in the core and is computed as weighted averages of portfolios of suitable core CDS.

The top panel of Figure 5 displays the time series of the value-weighted average CDS of firms in the periphery (solid line) and in the synthetic core (dotted line). Before the Italian lockdown, the two series overlap with each other, which indicates that in the absence of priced government guarantees, the average cost of credit protection for the two sets of firms coincides. When the COVID-19 shock hits, the portfolios diverge, along with perceptions of government support across 
EU regions, with CDS spreads in the synthetic core group on average some 16.9 bps higher than those in the actual periphery.

Reading this evidence through the lenses of the model yields the following insight. The periphery series reflects the pricing of credit risk for firms subject to bailout guarantees $\underline{J}^{P e r i}$ and average sensitivity $\kappa_{c}^{P e r i}$. By construction, the default intensity of synthetic core series has a loading $\kappa_{c}^{\text {Core }}$ to jumps in consumption growth but is exposed to $\underline{J}^{\text {Peri }}$, as it is a convex combination of spreads on peripheral entities. The difference between the two lines, conditional on the disaster taking place (and given that the pre-COVID differences are null), equals

$$
\begin{aligned}
{\left[C D S^{\text {Synth.Core }}-C D S^{\text {Peri }} \mid E=1\right] } & \approx(1-R)\left(\lambda^{\text {Synth.Core }}-\lambda^{\text {Peri }}\right) \\
& =(1-R)\left(\kappa_{c}^{\text {Core }}-\kappa_{c}^{\text {Peri }}\right) \underline{J}^{\text {Peri }}
\end{aligned}
$$

The positive difference over the period indicates that, when core firms are artificially exposed to less government support in the face of a rare disaster, their CDS spreads react on average more than those of peripheral ones. This fact points towards a larger sensitivity to disaster risk through their reliance on the bailout; namely, $\kappa_{c}^{\text {Core }}>\kappa_{c}^{\text {Peri }}$. From an economic viewpoint, debtholders of core firms foresee stronger government support when a disaster looms. Therefore, they expect a more aggressive truncation of their credit losses, and the pricing overweights favorable states of the world. Consistently, the disaster would have an even more dramatic effect on core default swaps when such government support is deemed to be lower or missing. ${ }^{30}$

Symmetrically, the bottom plot of Figure 5 displays the time series of the value-weighted average CDS of firms in the core (solid line) and synthetic periphery (dotted line). Again, we find that, in the pre-COVID period, differences are negligible. In the post-COVID subsample, the credit risk of companies in the core was always priced higher than those in the synthetic periphery, with the difference averaging about $6.5 \mathrm{bps}$.

In model terms, the synthetic periphery quantifies the credit risk of the synthetic portfolio of

\footnotetext{
${ }^{30}$ In line with this reasoning is the evidence in Correa et al. (2014) that the negative effect of sovereign credit downgrades on the performance of large banks is stronger in advanced economies, which are better positioned to extend support than emerging markets.
} 
core firms, which replicates the corporate spreads in the periphery had they been priced according to government support $\underline{J}^{\text {Core }}$. Proceeding as above, we can write

$$
\begin{aligned}
{\left[C D S^{\text {Core }}-C D S^{\text {Synth.Peri }} \mid E=1\right] } & \approx(1-R)\left(\lambda^{\text {Core }}-\lambda^{\text {Synth.Peri }}\right) \\
& =(1-R)\left(\kappa_{c}^{\text {Core }}-\kappa_{c}^{\text {Peri }}\right) \underline{J}^{\text {Core }}
\end{aligned}
$$

The 6.5 bps positive difference again confirms the conclusion from the previous analysis that core companies are more sensitive to bailout guarantees.

Taking the ratio of the average value of the two differences during the COVID sample, we obtain an estimate the ratio of priced bailout guarantees in the two regions:

$$
\frac{\left[C D S^{\text {Synth.Core }}-C D S^{\text {Peri }} \mid E=1\right]}{\left[C D S^{\text {Core }}-C D S^{\text {Synth.Peri }} \mid E=1\right]}=\frac{\underline{J}^{\text {Peri }}}{\underline{J}^{\text {Core }}}=\frac{0.00169}{0.00065}=2.60 .
$$

This figure reveals that, over the medium term, firms in the core are perceived as being insulated from (risk-neutral) default risk shocks that are 2.60 times larger than those on the periphery.

Overall, post-treatment differences between treated and synthetic units from both panels deliver the following two messages. First, core firms' spreads are characterized by a higher sensitivity to disaster risk relative to their peripheral counterparts, or $\kappa_{c}^{\text {Core }}>\kappa_{c}^{\text {Periphery }}$. Second, credit swap spreads signal sizable differences in government floors, with support that is expected to be

stronger in the core, or $\underline{J}^{\text {Core }}<\underline{J}^{\text {Peri }}$. According to Eq. (8), both these relations have the effect of amplifying the disaster-induced nexus in the core of the EU, consistent with the regression-based evidence in Section 3.

\section{Conclusions}

This work investigates the effect of the COVID-19 pandemic on credit risk spillovers between sovereign and domestic non-financial corporations in the Euro Area. Such externalities are generally deemed to result from a sovereign risk channel, which views spillovers as originated by the 
amplification of a negative demand shock caused by fiscal strains and the threat of tax hikes.

By contrast, we find that the pandemic triggered a significant increase in the elasticity of firms' credit default swaps to their sovereign only in countries with wide fiscal capacity. This finding suggests that a major determinant of the corporate-sovereign nexus in the wake of the Great Lockdown is the bailout channel, according to which spillovers result from the pricing of government support. The result is strongly robust to a wealth of economic and econometric sensitivity checks. It is also corroborated by systematic discounts over a standard credit risk model for larger firms at the core of the Euro Area, which are consistent with perceived sovereign fiscal capacity playing a key role when systemic tail risk materializes.

To illustrate the mechanisms at work, we propose a bailout-augmented asset pricing model featuring stochastic jumps in consumption growth. The model delivers a closed-form expression for the covariance between corporate and sovereign intensities of default, which depends on the amount of space for fiscal intervention. Through the lenses of the model, the disaster-induced spike in the corporate-sovereign nexus results from market participants' repricing of the expected value of government support to non-financial firms.

The application of a synthetic control method shows that CDS quotes embed the perception that, after the coronavirus outbreak, firms in the periphery of the Euro Area were on average about 2.6 times more exposed to a systemic shock on risk-neutral default intensity relative to firms in the EU core. This figure demonstrates that thoughtful fiscal capacity buffers are beneficial for the level of financing costs of domestic firms. 


\section{References}

Abadie, A., A. Diamond, and J. Hainmueller. 2010. Synthetic control methods for comparative case studies: Estimating the effect of California's tobacco control program. Journal of the American Statistical Association 105:493-505.

Acharya, V., I. Drechsler, and P. Schnabl. 2014. A pyrrhic victory? Bank bailouts and sovereign credit risk. The Journal of Finance 69:2689-739.

Acharya, V. V., and S. Steffen. 2020. The risk of being a fallen angel and the corporate dash for cash in the midst of COVID. The Review of Corporate Finance Studies 9:430-71.

Almeida, H., I. Cunha, M. A. Ferreira, and F. Restrepo. 2017. The real effects of credit ratings: The sovereign ceiling channel. The Journal of Finance 72:249-90.

Ang, A., and F. A. Longstaff. 2013. Systemic sovereign credit risk: Lessons from the U.S. and Europe. Journal of Monetary Economics 60:493-510.

Arellano, M., and O. Bover. 1995. Another look at the instrumental variable estimation of errorcomponents models. Journal of Econometrics 68:29-51.

Augustin, P., H. Boustanifar, J. Breckenfelder, and J. Schnitzler. 2018. Sovereign to corporate risk spillovers. Journal of Money, Credit and Banking 50:857-91.

Augustin, P., V. Sokolovski, M. G. Subrahmanyam, and D. Tomio. 2021. In sickness and in debt: The COVID-19 impact on sovereign credit risk. Journal of Financial Economics.

Augustin, P., M. G. Subrahmanyam, D. Y. Tang, and S. Q. Wang. 2014. Credit default swaps-A survey. Foundations and Trends ${ }^{\circledR}$ in Finance 9:1-196.

Bai, J., R. S. Goldstein, and F. Yang. 2019. The leverage effect and the basket-index put spread. Journal of Financial Economics 131:186-205.

Barro, R. J. 2006. Rare disasters and asset markets in the twentieth century. The Quarterly Journal of Economics 121:823-66.

Bedendo, M., and P. Colla. 2015. Sovereign and corporate credit risk: Evidence from the Eurozone. Journal of Corporate Finance 33:34-52.

Berndt, A., R. A. Jarrow, and C. Kang. 2007. Restructuring risk in credit default swaps: An empirical analysis. Stochastic Processes and Their Applications 117:1724-49.

Berndt, A., and I. Obreja. 2010. Decomposing European CDS returns. Review of Finance 14:189233.

Bevilaqua, J., G. B. Hale, and E. Tallman. 2020. Corporate yields and sovereign yields. Journal of International Economics 124:1-15.

Bharath, S. T., and T. Shumway. 2008. Forecasting default with the Merton distance to default model. The Review of Financial Studies 21:1339-69. 
Blanchard, O. 2019. Public debt and low interest rates. American Economic Review 109:1197-229.

Blundell, R., and S. Bond. 1998. Initial conditions and moment restrictions in dynamic panel data models. Journal of Econometrics 87:115-43.

Bocola, L. 2016. The pass-through of sovereign risk. Journal of Political Economy 124:879-926.

Brunnermeier, M. K., L. Garicano, P. R. Lane, M. Pagano, R. Reis, T. Santos, D. Thesmar, S. Van Nieuwerburgh, and D. Vayanos. 2016. The sovereign-bank diabolic loop and ESBies. American Economic Review 106:508-12.

Correa, R., K.-H. Lee, H. Sapriza, and G. A. Suarez. 2014. Sovereign credit risk, banks' government support, and bank stock returns around the world. Journal of Money, Credit and Banking 46:93-121.

Corsetti, G., K. Kuester, A. Meier, and G. J. Müller. 2013. Sovereign risk, fiscal policy, and macroeconomic stability. The Economic Journal 123:99-132.

Duffie, D. 1999. Credit swap valuation. Financial Analysts Journal 55:73-87.

Duffie, D., and K. J. Singleton. 2012. Credit risk: pricing, measurement, and management. Princeton, NJ: Princeton University Press.

Dunn, A., K. Hood, and A. Driessen. 2020. Measuring the effects of the COVID-19 pandemic on consumer spending using card transaction data. US Bureau of Economic Analysis Working Paper 2020-5.

Ehrmann, M., and M. Fratzscher. 2017. Euro area government bonds-Fragmentation and contagion during the sovereign debt crisis. Journal of International Money and Finance 70:26-44.

Elenev, V., T. Landvoigt, and S. Van Nieuwerburgh. 2020. Can the COVID bailouts save the economy? National Bureau of Economic Research Working Paper 27207.

Fahlenbrach, R., K. Rageth, and R. M. Stulz. 2020. How Valuable Is Financial Flexibility when Revenue Stops? Evidence from the COVID-19 Crisis. The Review of Financial Studies .

Farhi, E., and J. Tirole. 2018. Deadly embrace: Sovereign and financial balance sheets doom loops. The Review of Economic Studies 85:1781-823.

Gabaix, X. 2012. Variable rare disasters: An exactly solved framework for ten puzzles in macrofinance. The Quarterly Journal of Economics 127:645-700.

Gandhi, P., H. Lustig, and A. Plazzi. 2020. Equity is cheap for large financial institutions. The Review of Financial Studies 33:4231-71.

Gerding, F., T. Martin, and F. Nagler. 2020. Sovereign Debt and Equity Returns in the Face of Disaster. Working Paper, https://dx.doi.org/10.2139/ssrn.3572839.

Greppmair, S., S. Jank, and E. Smajlbegovic. 2020. Betting on disaster: short-selling activity during the COVID-19 pandemic. Working Paper, https://dx.doi.org/10.2139/ssrn.3638584. 
Hainmueller, J. 2012. Entropy balancing for causal effects: A multivariate reweighting method to produce balanced samples in observational studies. Political Analysis 20:25-46.

Hull, J. C. 2003. Options futures and other derivatives. New Delhi: Pearson Education India.

Jacob, M., R. Michaely, and M. A. Müller. 2018. Consumption taxes and corporate investment. The Review of Financial Studies 32:3144-82.

Kelly, B., H. Lustig, and S. Van Nieuwerburgh. 2016. Too-systemic-to-fail: What option markets imply about sector-wide government guarantees. American Economic Review 106:1278-1319.

Krishnamurthy, A., and W. Li. 2020. Dissecting mechanisms of financial crises: Intermediation and sentiment. National Bureau of Economic Research Working Paper 27088.

Krishnamurthy, A., and A. Vissing-Jorgensen. 2011. The effects of quantitative easing on interest rates: channels and implications for policy. National Bureau of Economic Research Working Paper 17555.

Lando, D. 2009. Credit risk modeling: Theory and applications. Princeton, NJ: Princeton University Press.

Lee, J., A. Naranjo, and S. Sirmans. 2016. Exodus from sovereign risk: Global asset and information networks in the pricing of corporate credit risk. The Journal of Finance 71:1813-6.

Longstaff, F. A., S. Mithal, and E. Neis. 2005. Corporate yield spreads: Default risk or liquidity? New evidence from the credit default swap market. The Journal of Finance 60:2213-53.

Longstaff, F. A., J. Pan, L. H. Pedersen, and K. J. Singleton. 2011. How sovereign is sovereign credit risk? American Economic Journal: Macroeconomics 3:75-103.

Mäkinen, T., L. Sarno, and G. Zinna. 2020. Risky bank guarantees. Journal of Financial Economics 136:490-522.

Merton, R. C. 1974. On the pricing of corporate debt: The risk structure of interest rates. The Journal of Finance 29:449-70.

Pagano, M., C. Wagner, and J. Zechner. 2020. Disaster resilience and asset prices. CEPR Discussion Paper 14773.

Pan, J., and K. J. Singleton. 2008. Default and recovery implicit in the term structure of sovereign CDS spreads. The Journal of Finance 63:2345-84.

Ramelli, S., and A. F. Wagner. 2020. Feverish stock price reactions to COVID-19. The Review of Corporate Finance Studies 9:622-55.

Rietz, T. A. 1988. The equity risk premium a solution. Journal of Monetary Economics 22:117-31.

Romer, C. D., and D. H. Romer. 2018. Phillips lecture-Why some times are different: Macroeconomic policy and the aftermath of financial crises. Economica 85:1-40. 
Sgherri, S., and E. Zoli. 2009. Euro area sovereign risk during the crisis. International Monetary Fund Working Paper 09222.

Veronesi, P., and L. Zingales. 2010. Paulson's gift. Journal of Financial Economics 97:339-68.

Wenzhi, D., R. Levine, C. Lin, and W. Xie. 2021. Corporate immunity to the COVID-19 pandemic. Journal of Financial Economics 141:802-30. 


\section{Appendix A: Principal Component Analysis}

To better appreciate the effect of the pandemic on the cross section of spreads, we conduct a principal component analysis (PCA), as in Berndt and Obreja (2010) and Longstaff et al. (2011), before and after the coronavirus outbreak. Given the marked differences in the level of CDS spreads (especially for sovereigns) and for consistency with our regression analysis, we perform the PCA on the correlation matrix of daily differences in log CDS spreads.

Table A.3 reports the percentage of variance explained by the first two principal components separately estimated on the panel of sovereign and corporate spreads, and on stock returns as benchmark. It is well established that Euro Area spreads have high commonality, mainly reflecting international risk appetite. For instance, Sgherri and Zoli (2009) point out that their comovement is increasing in stock volatility. Berndt and Obreja (2010) show that the role of the first factor in European corporate CDS spreads increased during the 2007-2009 financial crisis, and argue it mostly reflects disaster risk. In line with their findings, Table A.3 shows that the COVID-19 crisis increased the already high commonality in risk and returns of corporate firms in the Eurozone. In particular, the first factor accounts for as much as $70 \%$ of the comovement in the CDS spreads on the 123 European corporations in our sample. Interestingly, the strength of the common factor structure gets even more pronounced for credit risk than for equity, which suggests that the impact of the shock on debt markets was felt more strongly and broadly.

The surge in the importance of the common factor is even more pronounced for sovereign CDS spreads, as the role of the first component nearly doubles from $34 \%$ to $67 \%$ during the event period. Figure A.2 displays the loadings on the first principal component (i.e., the first eigenvector) of sovereign CDS across countries. Before the outbreak, the first principal component has a heavier loading on the periphery of the Union. The shock increases the loading on the core and reduces the loading on the periphery, thus resulting in larger similarities in the role of sovereigns and pushing toward higher integration in the Euro Area credit risk market.

\section{Appendix B: Proof of Proposition I}

Proof. Using a discrete-time version of Longstaff et al. (2005), the net present value (NPV) of the protection leg of a CDS can be expressed as

$$
\mathrm{PR}_{t}=\mathbb{E}_{t}\left[(1-R) \sum_{i=t}^{T} \lambda_{i} \exp \left(-\sum_{s=t}^{i}\left(r_{s}+\lambda_{s}\right)\right)\right]
$$

while the NPV of the premium leg is

$$
\mathbf{P}_{t}=\mathbb{E}_{t}\left[\operatorname{CDS}_{t} \sum_{i=t}^{T} \exp \left(-\sum_{s=t}^{i}\left(r_{s}+\lambda_{s}\right)\right)\right]
$$

In line with the literature and industry practice, we assume a constant recovery rate. Denote the 
discount factor by $D(t)$. Consider first the NPV of the protection leg

$$
\begin{aligned}
\mathrm{PR}_{t} & =(1-R) \mathbb{E}_{t}\left[\sum_{i=t}^{T} D(i) \lambda_{i} \exp \left(-\sum_{s=t}^{i} \lambda_{s}\right)\right] \\
& =(1-R)\left[\lambda_{t}+\mathbb{E}_{t}\left[\lambda_{t+1} e^{-\lambda_{t+1}-r_{t+1}}\right]+\mathbb{E}_{t}\left[\lambda_{t+2} e^{-\lambda_{t+1}-\lambda_{t+2}-r_{t+1}-r_{t+2}}\right]+\cdots\right]
\end{aligned}
$$

Evaluating the same quantity at $t+1$ yields

$$
\begin{aligned}
\mathrm{PR}_{t+1} & =(1-R) \mathbb{E}_{t+1}\left[\sum_{i=t+1}^{T} D(i) \lambda_{i} \exp \left(-\sum_{s=t}^{i} \lambda_{s}\right)\right] \\
& =(1-R)\left[\lambda_{t+1}+\mathbb{E}_{t+1}\left[\lambda_{t+2} e^{-\lambda_{t+2}-r_{t+2}}\right]+\mathbb{E}_{t+1}\left[\lambda_{t+3} e^{-\lambda_{t+2}-\lambda_{t+3}-r_{t+2}-r_{t+3}}\right]+\cdots\right]
\end{aligned}
$$

All shocks in the model are transitory. By a rational expectations argument, provided the Markov states are sufficiently persistent (i.e. for $\pi_{i i} \rightarrow 1 \forall i \in I$ ) successive discounted default intensities tend to the random walk model

$$
\lim _{\pi_{i i} \rightarrow 1} \sum_{i \in I}\left[\mathbb{E}_{t}\left[\lambda_{t+1} e^{-\lambda_{t+1}-r_{t+1}}\right] \mid p_{t}=p_{i}\right]=\lim _{\pi_{i i} \rightarrow 1} \sum_{i \in I}\left[\mathbb{E}_{t+1}\left[\lambda_{t+2} e^{-\lambda_{t+2}-r_{t+2}} \mid p_{t+1}=p_{i}\right]\right]
$$

Therefore,

$$
\mathbb{E}_{t}\left[\lambda_{t+1} e^{-\lambda_{t+1}-r_{t+1}}\right]=\mathbb{E}_{t+1}\left[\lambda_{t+2} e^{-\lambda_{t+2}-r_{t+2}}\right] \quad \text { a.s. }
$$

Replacing (18) in (15) and (16) and rearranging terms yields

$$
\begin{aligned}
\Delta \mathrm{PR}_{t+1} & =(1-R)\left[\lambda_{t+1}-\lambda_{t}-\mathbb{E}_{t}\left[D(T) \lambda_{T} \exp \left(-\sum_{s=t}^{T} \lambda_{s}\right)\right]\right] \\
& \approx(1-R) \Delta \lambda_{t+1}
\end{aligned}
$$

The approximation accuracy increases in time to maturity. Consider now the NPV of the premium leg at time $t$

$$
\begin{aligned}
\mathrm{P}_{t} & =\mathbb{E}_{t}\left[\operatorname{CDS}_{t} \sum_{i=t}^{T} \exp \left(-\sum_{s=t}^{i}\left(r_{s}+\lambda_{s}\right)\right)\right] \\
& =\operatorname{CDS}_{t}\left[1+\mathbb{E}_{t}\left[e^{-\lambda_{t+1}-r_{t+1}}\right]+\mathbb{E}_{t}\left[e^{-\lambda_{t+1}-\lambda_{t+2}-r_{t+1}-r_{t+2}}\right]+\cdots\right]
\end{aligned}
$$


At time $t+1$, the value of the contract for the protection seller is

$$
\begin{aligned}
\mathrm{P}_{t+1} & =\mathbb{E}_{t+1}\left[\operatorname{CDS}_{t+1} \sum_{i=t+1}^{T} \exp \left(-\sum_{s=t+1}^{i}\left(r_{s}+\lambda_{s}\right)\right)\right] \\
& =\mathrm{CDS}_{t+1}\left[1+\mathbb{E}_{t+1}\left[e^{-\lambda_{t+2}-r_{t+2}}\right]+\mathbb{E}_{t+1}\left[e^{-\lambda_{t+2}-\lambda_{t+3}-r_{t+2}-r_{t+3}}\right]+\cdots\right]
\end{aligned}
$$

Disregarding the term $\mathbb{E}_{t}\left[\exp \left(-\sum_{s=t+1}^{T}\left(r_{s}+\lambda_{s}\right)\right)\right] \approx 0$,

$$
\Delta \mathrm{P}_{t+1}=\Delta \mathrm{CDS}_{t+1}
$$

Equating the changes in NPV of buyer's and seller's legs completes the proof

$$
\Delta \mathrm{CDS}_{t+1} \approx(1-R) \Delta \lambda_{t+1}
$$

The quality of the approximation increases in time to maturity $T-t$.

\section{Appendix C: Proof of Proposition II}

Proof. Disaster-induced changes in default intensity are piecewise linear in $J_{t+1}^{\lambda}$ for both government and corporate debt issuers (see Figure A.3). Remember that $\underline{J}$ is deterministic. Therefore,

$$
\begin{gathered}
\mathbb{E}_{t}\left[\max \left\{J_{t+1}^{\lambda}-\underline{J}, 0\right\}\right]=(1-\Phi)\left(\theta_{\lambda}+\frac{\delta_{\lambda} \varphi}{1-\Phi}-\underline{J}\right)=(1-\Phi)\left(\theta_{\lambda}-\underline{J}\right)+\delta_{\lambda} \varphi \\
\mathbb{E}_{t}\left[\min \left\{J_{t+1}^{\lambda}, \underline{J}\right\}\right]=\left[\underline{J}(1-\Phi)+\Phi\left(\theta_{\lambda}-\frac{\delta_{\lambda} \varphi}{\Phi}\right)\right]
\end{gathered}
$$

The terms $\frac{\delta_{\lambda} \varphi}{1-\Phi}$ and $-\frac{\delta_{\lambda} \varphi}{\Phi}$ come from the truncation of the lower and upper tails of the distribution of the government default intensity jump at $\underline{J}$, respectively. Moreover,

$$
\begin{aligned}
\mathbb{E}_{t}\left[\min \left\{J_{t+1}^{\lambda}, \underline{J}\right\} \max \left\{J_{t+1}^{\lambda}-\underline{J}, 0\right\}\right] & =(1-\Phi) \mathbb{E}\left[\min \left\{J_{t+1}^{\lambda}, \underline{J}\right\} \max \left\{J_{t+1}^{\lambda}-\underline{J}, 0\right\} \mid J_{t+1}^{\lambda}>\underline{J}\right]+0 \\
& =(1-\Phi) \mathbb{E}\left[\underline{J}\left(J_{t+1}^{\lambda}-\underline{J}\right) \mid J_{t+1}^{\lambda}>\underline{J}\right] \\
& =(1-\Phi) \underline{J} \mathbb{E}\left[\left(J_{t+1}^{\lambda}-\underline{J}\right) \mid J_{t+1}^{\lambda}>\underline{J}\right] \\
& =(1-\Phi) \underline{J}\left(\theta_{\lambda}+\frac{\delta_{\lambda} \varphi}{1-\Phi}-\underline{J}\right) \\
& =\underline{J} \mathbb{E}_{t}\left[\max \left\{J_{t+1}^{\lambda}-\underline{J}, 0\right\}\right] .
\end{aligned}
$$


For clarity of notation, let us use $J_{t+1}^{c}=\min \left\{J_{t+1}^{\lambda}, \underline{J}\right\}$ and denote thorugh $\lambda_{t}^{N D}$ and $\lambda_{t}^{D}$ the intensity of a credit event in a non disaster and disaster case, respectively. By definition,

$$
\begin{aligned}
\operatorname{Cov}\left(\Delta \lambda_{t+1}^{g}, \Delta \lambda_{t+1}^{c}\right) & =\left(1-p_{i}\right) \mathbb{E}_{t}\left[\Delta \lambda_{t+1}^{g, N D} \Delta \lambda_{t+1}^{c, N D}\right]+p_{i} \mathbb{E}_{t}\left[\Delta \lambda_{t+1}^{g, D} \Delta \lambda_{t+1}^{c, D}\right] \\
& -\left[\left(1-p_{i}\right) \mathbb{E}_{t}\left[\Delta \lambda_{t+1}^{g, N D}\right]+p_{i} \mathbb{E}_{t}\left[\Delta \lambda_{t+1}^{g, D}\right]\right]\left[\left(1-p_{i}\right) \mathbb{E}_{t}\left[\Delta \lambda_{t+1}^{c, N D}\right]+p_{i} \mathbb{E}_{t}\left[\Delta \lambda_{t+1}^{c, D}\right]\right] \\
& =\left(1-p_{i}\right) \mathbb{E}_{t}\left[\left(\mu_{t}^{g}+\phi_{g} \sigma_{i} \eta_{t+1}\right)\left(\mu_{t}^{c}+\phi_{c} \sigma_{i} \eta_{t+1}+\sigma_{c} \varepsilon_{t+1}\right)\right] \\
& +p_{i} \mathbb{E}_{t}\left[\left(\mu_{t}^{g}+\phi_{g} \sigma_{i} \eta_{t+1}+\max \left\{J_{t+1}^{\lambda}-\underline{J}, 0\right\}\right)\left(\mu_{t}^{c}+\phi_{c} \sigma_{i} \eta_{t+1}+\sigma_{c} \varepsilon_{t+1}+\kappa_{c} J_{t+1}^{c}\right)\right] \\
& -\left[\left(1-p_{i}\right) \mathbb{E}_{t}\left[\mu_{t}^{g}+\phi_{g} \sigma_{i} \eta_{t+1}\right]+p_{i} \mathbb{E}_{t}\left[\mu_{t}^{g}+\phi_{g} \sigma_{i} \eta_{t+1}+\max \left\{J_{t+1}^{\lambda}-\underline{J}, 0\right\}\right]\right] \\
& \times\left[\left(1-p_{i}\right) \mathbb{E}_{t}\left[\mu_{t}^{c}+\phi_{c} \sigma_{i} \eta_{t+1}+\sigma_{c} \varepsilon_{t+1}\right]+p_{i} \mathbb{E}_{t}\left[\mu_{t}^{c}+\phi_{c} \sigma_{i} \eta_{t+1}+\sigma_{c} \varepsilon_{t+1}+\kappa_{c} J_{t+1}^{c}\right]\right] \\
& =\left(1-p_{i}\right)\left[\mu_{t}^{g} \mu_{t}^{c}+\phi_{g} \phi_{c} \sigma_{i}^{2}\right]+p_{i}\left[\mu_{t}^{g} \mu_{t}^{c}+\mu_{t}^{g} \kappa_{c} \mathbb{E}_{t}\left[J_{t+1}^{c}\right]+\mu_{t}^{c} \mathbb{E}_{t} \max \left\{J_{t+1}^{\lambda}-\underline{J}, 0\right\}\right. \\
& +\phi_{g} \phi_{b} \sigma_{i}^{2}+\kappa_{c} \mathbb{E}_{t}\left[J_{t+1}^{c} \max \left\{J_{t+1}^{\lambda}-\underline{J}, 0\right\}\right]-\mu_{t}^{g} \mu_{t}^{c} \\
& -p_{i}\left[\mu_{t}^{g} \kappa_{c} \mathbb{E}_{t}\left[J_{t+1}^{c}\right]+\mu_{t}^{c} \mathbb{E}_{t}\left[\max \left\{J_{t+1}^{\lambda}-\underline{J}, 0\right\}\right]\right]-p_{i}^{2} \kappa_{c} \mathbb{E}_{t}\left[\max \left\{J_{t+1}^{\lambda}-\underline{J}, 0\right\}\right] \mathbb{E}_{t}\left[J_{t+1}^{c}\right] \\
& =\phi_{g} \phi_{c} \sigma_{i}^{2}+p_{i} \kappa_{c} \mathbb{E}_{t}\left[J_{t+1}^{c} \max \left\{J_{t+1}^{\lambda}-\underline{J}, 0\right\}\right]-p_{i}^{2} \kappa_{c} \mathbb{E}_{t}\left[\max \left\{J_{t+1}^{\lambda}-\underline{J}, 0\right\}\right] \mathbb{E}_{t}\left[J_{t+1}^{c}\right] .
\end{aligned}
$$

Using Eq. C.3 to simplify the expected value of the product of jumps,

$$
\begin{aligned}
\operatorname{Cov}\left(\Delta \lambda_{t+1}^{g}, \Delta \lambda_{t+1}^{c}\right) & =\phi_{g} \phi_{c} \sigma_{i}^{2}+p_{i} \kappa_{c} \underline{J} \mathbb{E}_{t}\left[\max \left\{J_{t+1}^{\lambda}-\underline{J}, 0\right\}\right]-p_{i}^{2} \kappa_{c} \mathbb{E}_{t}\left[\max \left\{J_{t+1}^{\lambda}-\underline{J}, 0\right\}\right] \mathbb{E}_{t}\left[J_{t+1}^{c}\right] \\
& =\phi_{g} \phi_{c} \sigma_{i}^{2}+\underbrace{\phi_{g} \phi_{c} \sigma_{i}^{2}}_{\substack{\text { Ex-disaster } \\
\text { Term }}}+\underbrace{p_{i} \kappa_{c} \mathbb{E}_{t}\left[\max \left\{J_{t+1}^{\lambda}-\underline{J}, 0\right\}\right]\left(\underline{J}-p_{i} \min \left\{J_{t}^{\lambda}, \underline{J}\right\}\right)}_{\text {Disaster Risk Term }} .
\end{aligned}
$$

Substitute Eq. C.1 and C.2 to obtain

$\operatorname{Cov}\left(\Delta \lambda_{t+1}^{g}, \Delta \lambda_{t+1}^{c}\right)=\phi_{g} \phi_{c} \sigma_{i}^{2}+p_{i} \kappa_{c}\left((1-\Phi)\left(\theta_{\lambda}-\underline{J}\right)+\delta_{\lambda} \varphi\right)\left(\underline{J}-p_{i}\left[\underline{J}(1-\Phi)+\Phi\left(\theta_{\lambda}-\frac{\delta_{\lambda} \varphi}{\Phi}\right)\right]\right)$.

Suppose for simplicity $\delta_{\lambda}=1$, so that $\Phi=\int_{-\infty}^{\underline{J}-\theta_{\lambda}} \frac{e^{-t^{2} / 2}}{\sqrt{2 \pi}} d t$. By Leibniz integration rule, $\frac{\partial \Phi}{\partial \underline{J}}=\varphi$. Moreover, as $\varphi=\frac{1}{\sqrt{2 \pi}} e^{\frac{-\left(\underline{J}-\theta_{\lambda}\right)^{2}}{2}}, \frac{\partial \varphi}{\partial \underline{J}}=\left(\theta_{\lambda}-\underline{J}\right) \varphi$. 


$$
\begin{aligned}
\frac{\partial \text { Disaster Term }}{\partial \underline{J}} & \stackrel{\text { up to } p_{i} \kappa_{c}}{\propto}-\left(\underline{J}-p_{i} \mathbb{E}_{t}\left[J_{t+1}^{c}\right]\right)[1-\Phi]+\mathbb{E}_{t}\left[\max \left\{J_{t+1}^{\lambda}-\underline{J}, 0\right\}\left[1-p_{i}(1-\Phi)\right]\right. \\
& =-\underline{J}(1-\Phi)+\mathbb{E}_{t}\left[\max \left\{J_{t+1}^{\lambda}-\underline{J}, 0\right\}\right] \\
& -\underbrace{p_{i}(1-\Phi)\left(\mathbb{E}_{t}\left[J_{t+1}^{c}\right]+\mathbb{E}_{t}\left[\max \left\{J_{t+1}^{\lambda}-\underline{J}, 0\right\}\right]\right)}_{>0 \text { since } \Phi<1 \text { and } \underline{J} \text { and } \theta_{\lambda} \text { are both } \geq 0} \\
& <-\underline{J}(1-\Phi)+\mathbb{E}_{t}\left[\max \left\{J_{t+1}^{\lambda}-\underline{J}, 0\right\}\right] \\
& <-\underline{J}(1-\Phi)+(1-\Phi)\left(\theta_{\lambda}-\underline{J}\right)+\varphi .
\end{aligned}
$$

Therefore, provided $\underline{J}>0.5\left(\theta_{\lambda}+\frac{\varphi}{1-\Phi}\right)$, the derivative is negative. In words, the disaster risk term is increasing in the extent of bailout guarantees as long as the government does not take on too much risk relative to the private sector. The mapping between default intensities and CDS premia established by Proposition I completes the proof.

\section{Appendix D: Synthetic Control Method}

Formally, consider the following approach. For each firm in a given region of the Euro Area (whether core or periphery), we select a combination of firms in the other region to mimic its performance. Since the procedure is computationally intensive, the estimation in Abadie et al. (2010) is constrained on a subsample of 250 trading days. We use the first 150 days prior to the event date (February 24, 2020) as a training sample, where the optimal replicating portfolio is constructed to minimize the distance between treatment and synthetic control over a set of predictor variables. For every treated unit, the weight given to each variable is a function of its explanatory power for the outcome variable, the five-year tenor CDS spread. In the out-of-sample period (i.e., the 100 days following the event date), the synthetic performance of a quote is evaluated from the evolution of the quotes among the constituents of the approximating portfolio. In sum, akin to event-study approaches, we identify the replicating portfolio using the pre-COVID-19 period and evaluate its performance afterwards.

We repeat this procedure for all firms in the sample. For each region, the quotes of the replicating portfolios are then averaged with weights corresponding to the market capitalization of the treated unit. In line with the literature, we drop units with large pre-treatment root mean square prediction error (RMSPE). This procedure results in a portfolio of CDS that reference firms in either of the two regions replicating the performance of the value-weighted average CDS spread in the other region. 

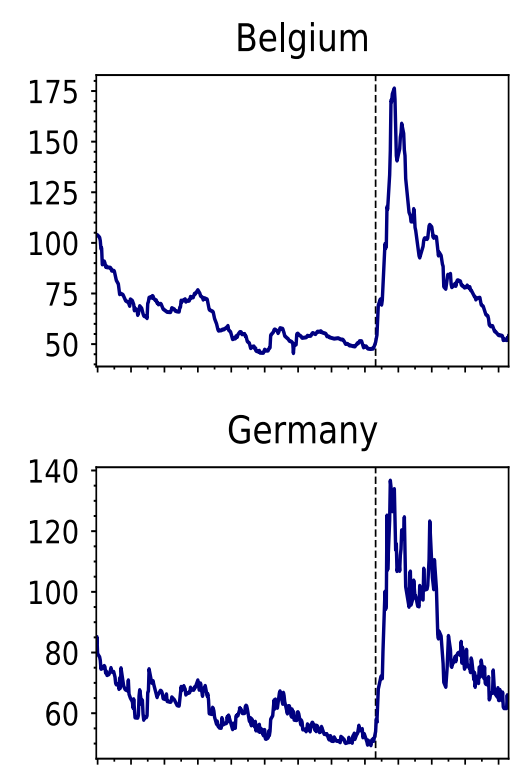

Netherlands

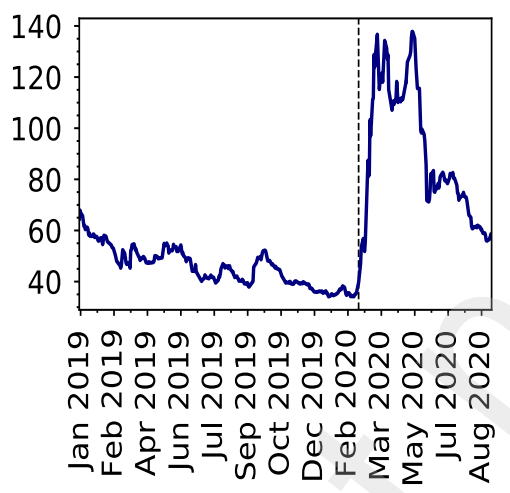

Finland

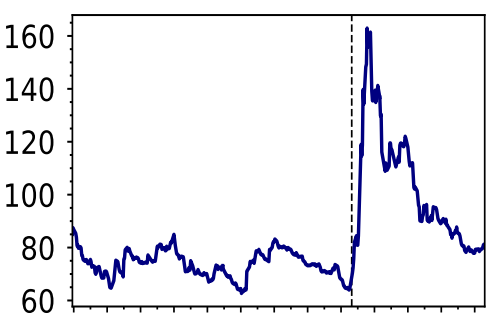

Greece

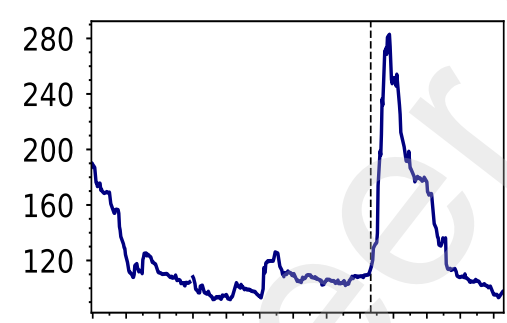

Portugal

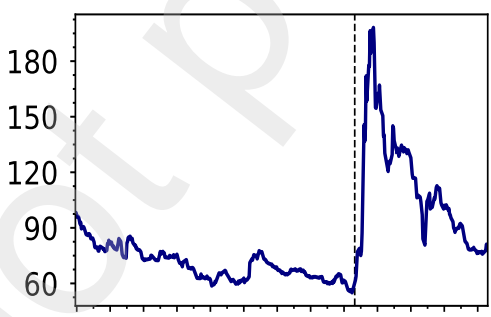

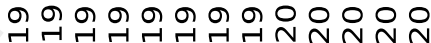

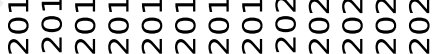

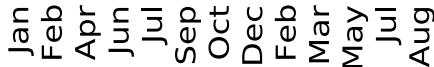

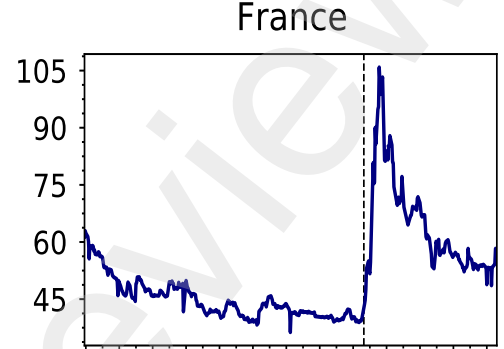

Italy

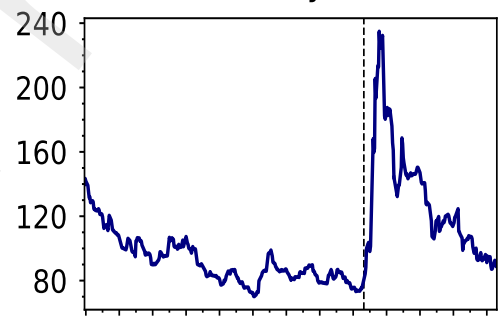

Spain

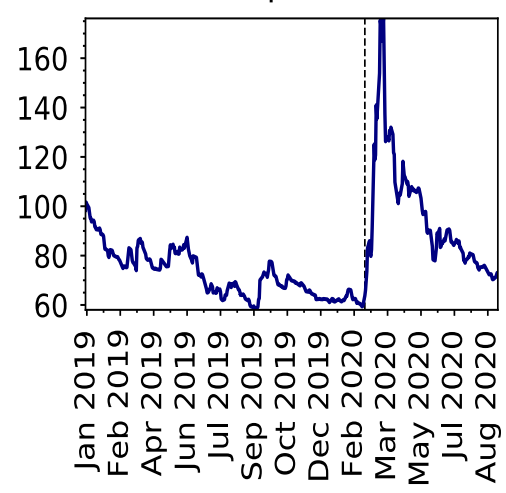

FIGURE 1: Euro Area corporate CDS: This figure plots the value-weighted average corporate CDS spread in basis points for firms headquartered in the nine countries in our sample over the period from January 1, 2019 to September 10, 2020 (443 trading days). The dashed vertical line marks the beginning of the first Italian lockdown on February 24, 2020. 

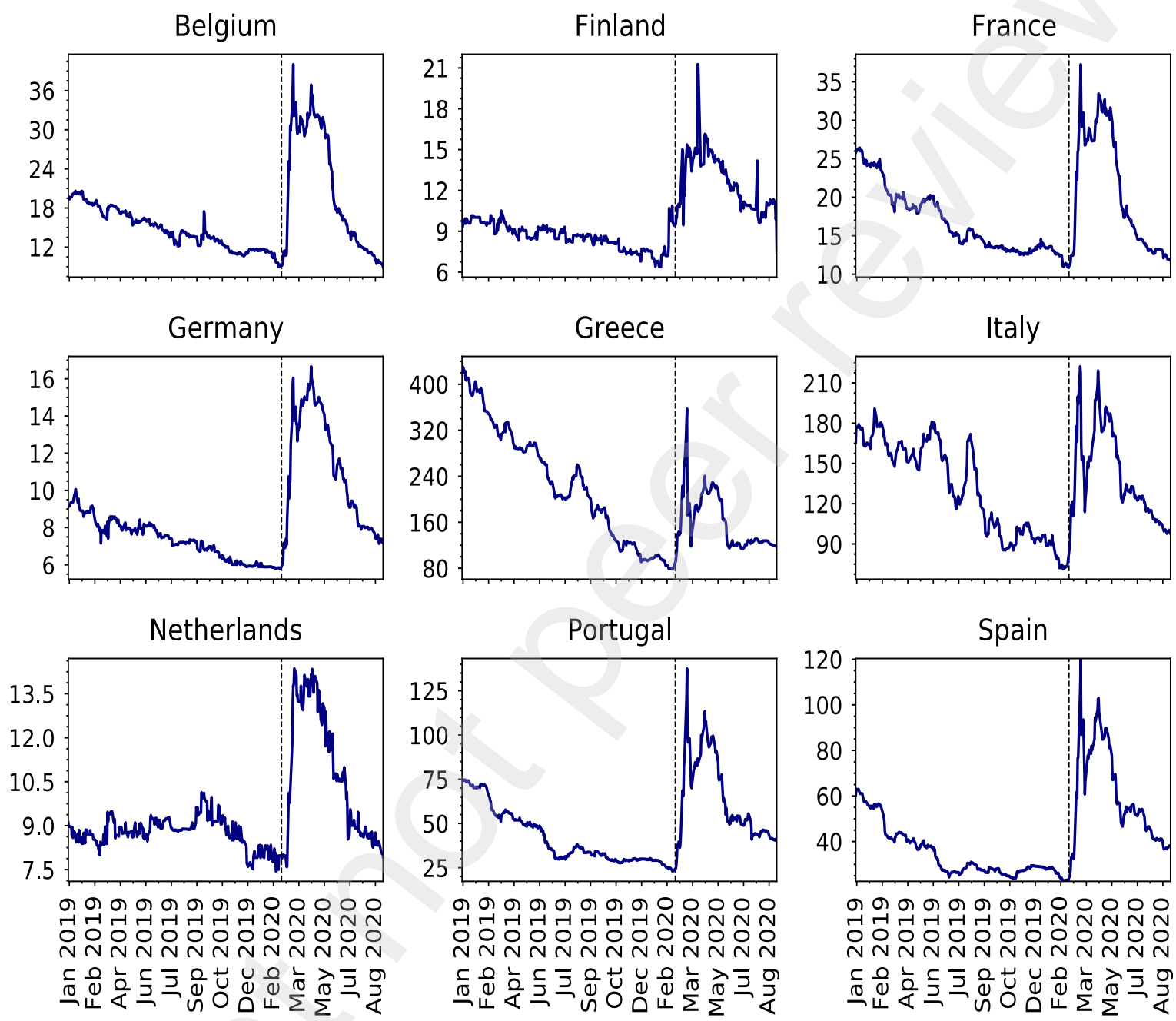

FIGURE 2: Euro Area sovereign CDS: This figure plots sovereign CDS spreads in basis points for the nine countries in our sample over the period from January 1, 2019 to September 10, 2020 (443 trading days). The dashed vertical line marks the beginning of the first Italian lockdown on February 24, 2020. 

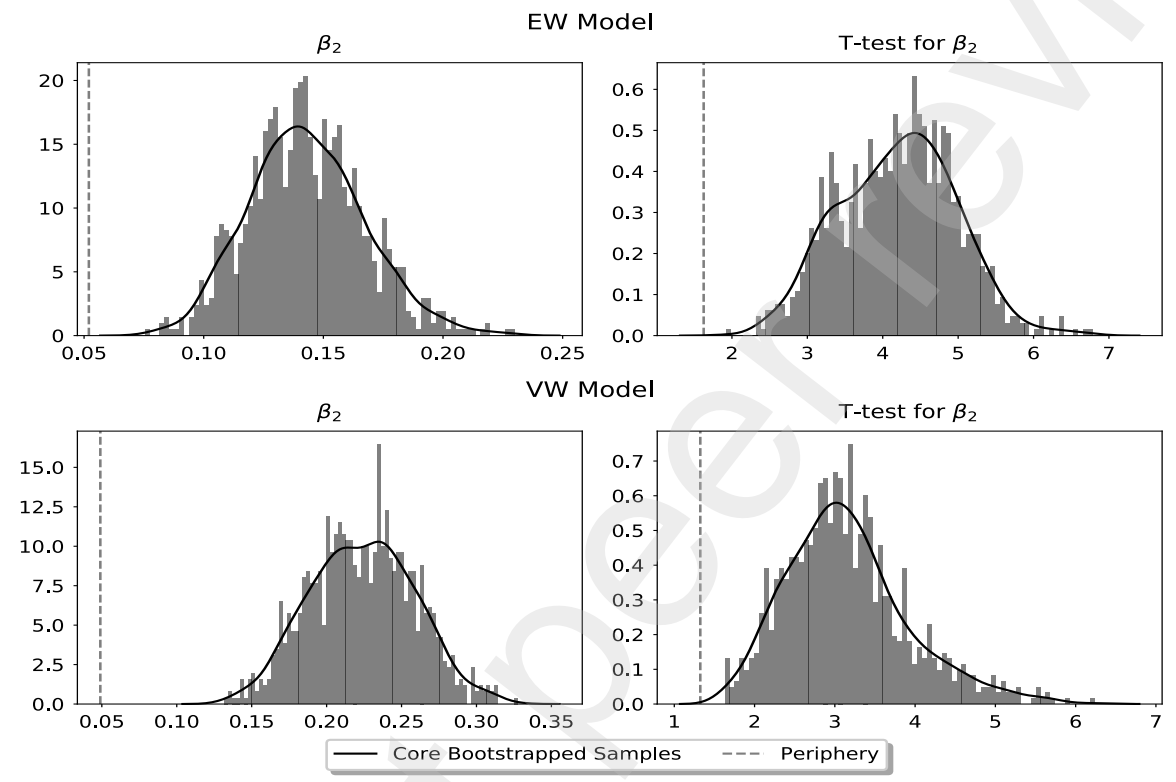

FIGURE 3: Bootstrap exercise: In each bootstrap run, we match every firm in the periphery with a random firm in the core in same sector classification. We then estimate our baseline panel regression on this randomized sample of core firms, whose size and industrial composition match (by design) those in the periphery, store the resulting coefficients and standard errors, and repeat the procedure 1,000 times. The figure plots the distributions of the $\beta_{2}$ coefficient (left panels) and its $t$-statistic (right panels) for the equally weighted (top panels) and market cap-weighted models across the 1,000 randomized core samples. The dotted line in each panel marks the corresponding estimate for the actual periphery from Table 2. 


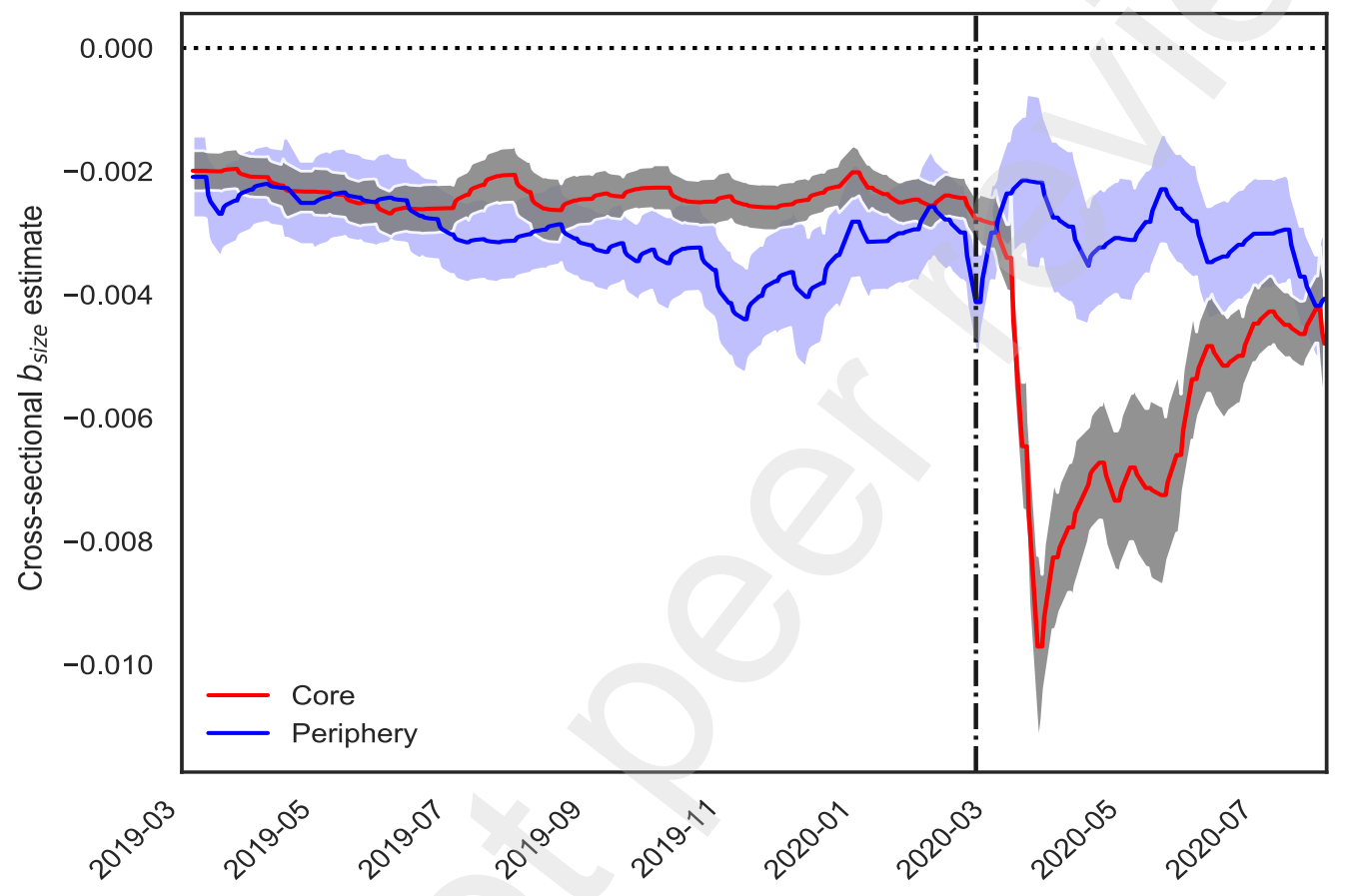

FIGURE 4: Deviations of CDS from fundamental credit risk as function of size: We calculate the model-implied CDS rate from the Merton (1974) model using Bharath and Shumway's (2008) measure of distance to default (DD). We then estimate cross-sectional weekly regressions of the form $\operatorname{CDS}_{i t}=$ $a_{t}+b_{1 t}$ Merton Spread $_{i t}+b_{2 t}$ Size $_{i t}+b_{3 t}$ Leverage $_{i t}+\varepsilon_{i t}$, separately for observations in the core and periphery. The plot displays the four-week trailing average relative to the time series of the resulting coefficient on size, $b_{2 t}$, with shaded areas denoting one standard deviation bands. The dash-dot vertical line marks the begin of the COVID-19 sample on February 24, 2020. 

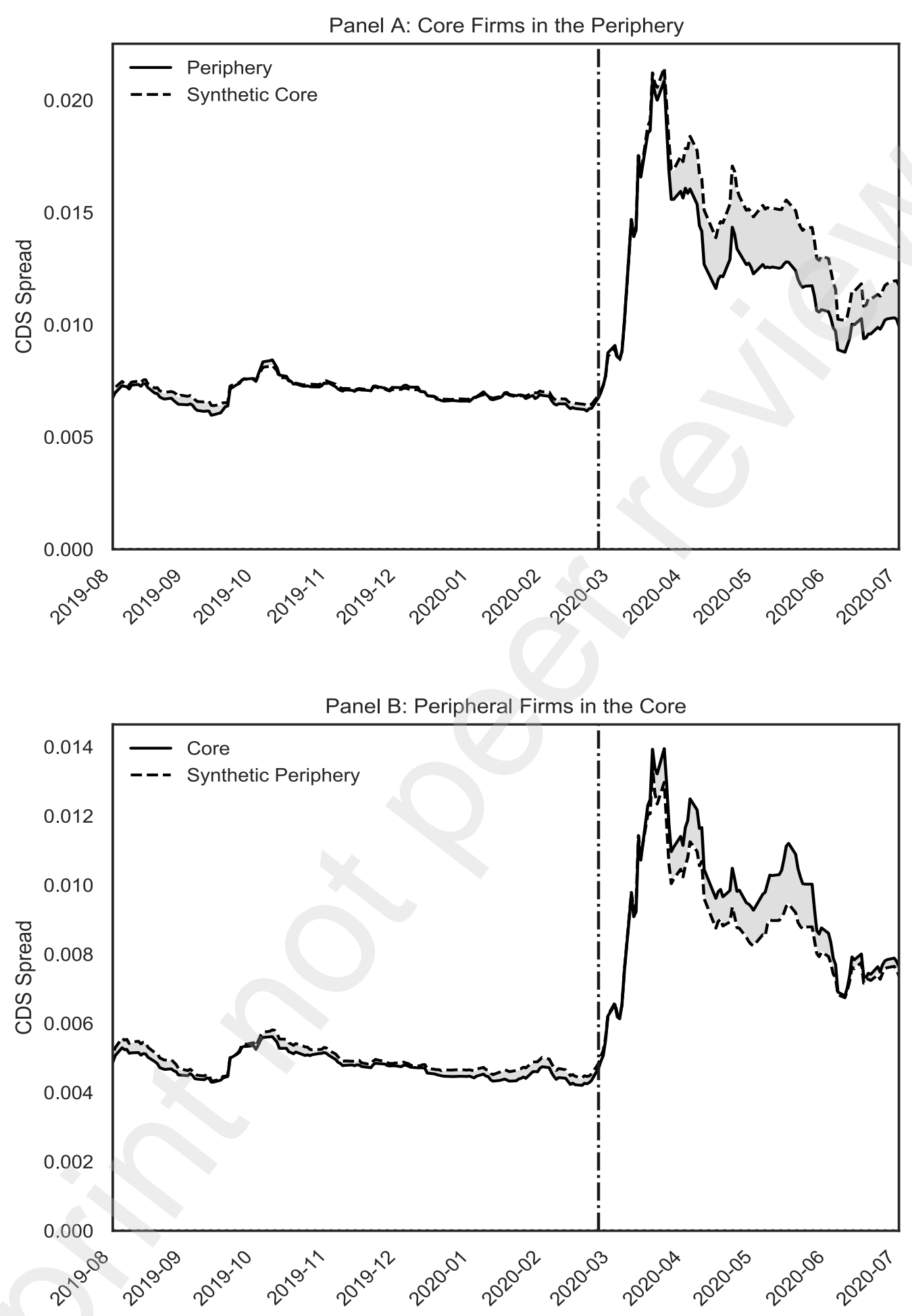

FIGURE 5: Synthetic control method: This figure plots the value-weighted average CDS spread (solid line) and its synthetic counterfactual (dashed line), which estimates the value-weighted average pricing of firms' credit risk had they been headquartered in the other region of the Euro Area. Panel (A) shows firms in the periphery of the Union. Panel (B) refers to firms in core countries. The dash-dot vertical line marks the begin of the COVID-19 sample on February 24, 2020. 


\section{TABLE 1: Summary statistics}

The table presents summary statistics of the sample. Panel A reports statistics of 5-year CDS spreads for our sample of non-financial firms and their sovereigns organized by country and region. Core countries are Belgium, Finland, France, Germany, and the Netherlands, while countries in the periphery are Greece, Italy, Portugal, and Spain. The data are daily from January 1, 2019 to September 10, 2020 (443 trading days). Panel B outlines country and regional averages of firms' balance sheet characteristics that are used in our analysis, as of fiscal year 2019.

\begin{tabular}{|c|c|c|c|c|c|c|c|c|c|}
\hline \multirow[b]{3}{*}{ Country } & \multicolumn{9}{|c|}{ Panel A: CDS spreads } \\
\hline & \multicolumn{5}{|c|}{ Corporate } & & \multicolumn{3}{|c|}{ Sovereign } \\
\hline & Obs. & Firms & Mean & Median & Std. Dev. & & Mean & Median & Std. Dev. \\
\hline Belgium & 2,573 & 6 & 0.0101 & 0.0067 & 0.0078 & & 0.0017 & 0.0014 & 0.0006 \\
\hline Finland & 3,340 & 8 & 0.0113 & 0.0084 & 0.0100 & & 0.0010 & 0.0009 & 0.0002 \\
\hline France & 17,233 & 40 & 0.0121 & 0.0057 & 0.0270 & & 0.0018 & 0.0016 & 0.0006 \\
\hline Germany & 13,824 & 33 & 0.0120 & 0.0073 & 0.0174 & & 0.0008 & 0.0008 & 0.0003 \\
\hline Netherlands & 5,195 & 12 & 0.0064 & 0.0039 & 0.0062 & & 0.0009 & 0.0009 & 0.0002 \\
\hline Core & 42,165 & 99 & 0.0112 & 0.0063 & 0.0205 & & 0.0013 & 0.0012 & 0.0006 \\
\hline Greece & 862 & 2 & 0.0255 & 0.0257 & 0.0178 & & 0.0204 & 0.0191 & 0.0092 \\
\hline Italy & 4,705 & 11 & 0.0156 & 0.0090 & 0.0129 & & 0.0134 & 0.0131 & 0.0035 \\
\hline Portugal & 866 & 2 & 0.0085 & 0.0071 & 0.0041 & & 0.0049 & 0.0045 & 0.0021 \\
\hline Spain & 3,897 & 9 & 0.0091 & 0.0064 & 0.0060 & & 0.0043 & 0.0038 & 0.0019 \\
\hline Periphery & 10,330 & 24 & 0.0133 & 0.0087 & 0.0119 & & 0.0098 & 0.0091 & 0.0066 \\
\hline \multirow[t]{4}{*}{ Total } & 52,495 & 123 & 0.0116 & 0.0067 & 0.0191 & & 0.0030 & 0.0013 & 0.0045 \\
\hline & \multicolumn{9}{|c|}{ Panel B: Firm characteristics } \\
\hline & \multicolumn{2}{|c|}{ Debt/Assets } & \multicolumn{2}{|c|}{ Market Cap } & \multicolumn{2}{|c|}{ Volatility } & \multicolumn{2}{|c|}{ Market Beta } & Rating \\
\hline & Mean & Std. Dev. & Mean & Std. Dev. & Mean & Std. Dev. & Mean & Std. Dev. & Mean \\
\hline Belgium & 33.34 & 14.53 & 46.34 & 58.90 & 0.2230 & 0.0420 & 0.9063 & 0.5355 & AA \\
\hline Finland & 21.11 & 12.14 & 10.64 & 6.71 & 0.30715 & 0.0902 & 1.366 & 0.5632 & AA \\
\hline France & 30.29 & 11.70 & 32.37 & 41.90 & 0.2453 & 0.0654 & 0.9666 & 0.3521 & AA \\
\hline Germany & 29.04 & 13.29 & 29.49 & 27.86 & 0.2839 & 0.0683 & 0.9968 & 0.3979 & AA \\
\hline Netherlands & 31.93 & 16.97 & 29.07 & 25.67 & 0.2589 & 0.0789 & 1.036 & 0.3576 & AA \\
\hline Core & 29.45 & 13.50 & 29.71 & 35.45 & 0.2642 & 0.0735 & 1.0176 & 0.4137 & AA \\
\hline Greece & 34.03 & 1.66 & 5.85 & 2.06 & 0.3001 & 0.0959 & 0.7778 & 0.2326 & $\mathrm{~A}$ \\
\hline Italy & 34.56 & 14.89 & 21.08 & 24.55 & 0.2598 & 0.0694 & 0.8420 & 0.2815 & AA \\
\hline Portugal & 36.43 & 5.71 & 13.20 & 0.8456 & 0.2198 & 0.0211 & 0.7694 & 0.0095 & AA \\
\hline Spain & 42.05 & 10.02 & 22.67 & 14.67 & 0.2085 & 0.0351 & 0.6849 & 0.2267 & $\mathrm{AA}$ \\
\hline Periphery & 38.09 & 12.18 & 20.11 & 18.77 & 0.2350 & 0.0620 & 0.7601 & 0.2498 & AA \\
\hline Total & 31.04 & 13.68 & 27.94 & 33.22 & 0.2588 & 0.0724 & 0.9702 & 0.4014 & AA \\
\hline
\end{tabular}




\section{TABLE 2: Corporate-sovereign nexus, baseline model}

The table reports estimates from the panel regression in Eq.(1), relating changes in log corporate CDS spreads to changes in log CDS spreads of the corresponding sovereigns and firm-specific and aggregate variables. The dummy $E$ equals one during the COVID-19 period (defined as the days after February 24, 2020) and zero otherwise. Results are reported for the equally weighted model (columns 1 and 2), for the equity market capitalization-weighted model (columns 3 and 4), and for the entropy-balanced model (columns 5 and 6). The models are estimated separately for countries in the core (Belgium, Finland, France, Germany, and the Netherlands) and the periphery (Greece, Italy, Portugal, and Spain). Robust standard errors clustered at the firm level are reported in parentheses. One, two, and three asterisks denote statistical significance at the $0.10,0.05$, and 0.01 levels, respectively.

\begin{tabular}{|c|c|c|c|c|c|c|}
\hline \multirow[b]{3}{*}{ Variables } & \multirow{2}{*}{\multicolumn{2}{|c|}{$\begin{array}{l}\text { (1) } \\
\text { Equally Weighted }\end{array}$}} & \multirow{2}{*}{\multicolumn{2}{|c|}{$\begin{array}{l}\text { (3) } \\
\text { Value Weighted }\end{array}$}} & \multirow{2}{*}{\multicolumn{2}{|c|}{$\begin{array}{l}(5) \\
\text { Entropy Balanced }\end{array}$}} \\
\hline & & & & & & \\
\hline & Core & Periphery & Core & Periphery & Core & Periphery \\
\hline$\Delta \log (\mathrm{CDS} \text { sovereign })_{j t}$ & $\begin{array}{l}0.127 * * * \\
(0.013)\end{array}$ & $\begin{array}{l}0.208 * * * \\
(0.036)\end{array}$ & $\begin{array}{c}0.170 * * * \\
(0.015)\end{array}$ & $\begin{array}{l}0.325 * * * \\
(0.037)\end{array}$ & $\begin{array}{l}0.126^{* * * *} \\
(0.013)\end{array}$ & $\begin{array}{c}0.294 * * * \\
(0.040)\end{array}$ \\
\hline$\Delta \log (\mathrm{CDS} \text { sovereign })_{j t} \times E$ & $\begin{array}{l}0.125 * * * \\
(0.016)\end{array}$ & $\begin{array}{c}0.052 \\
(0.032)\end{array}$ & $\begin{array}{c}0.151 * * * \\
(0.025)\end{array}$ & $\begin{array}{c}0.049 \\
(0.037)\end{array}$ & $\begin{array}{c}0.124 * * * \\
(0.016)\end{array}$ & $\begin{array}{c}0.008 \\
(0.044)\end{array}$ \\
\hline$\Delta \log (\mathrm{CDS} \text { corp })_{i j t-1}$ & $\begin{array}{l}0.162 * * * \\
(0.040)\end{array}$ & $\begin{array}{c}0.133 * * * \\
(0.043)\end{array}$ & $\begin{array}{c}0.095 * * * \\
(0.022)\end{array}$ & $\begin{array}{l}0.168 * * * \\
(0.013)\end{array}$ & $\begin{array}{l}0.165^{* * * *} \\
(0.041)\end{array}$ & $\begin{array}{c}0.149 * * * \\
(0.020)\end{array}$ \\
\hline$\Delta \log (\operatorname{CDS} \text { corp })_{i j t-1} \times E$ & $\begin{array}{l}-0.029 \\
(0.042)\end{array}$ & $\begin{array}{c}0.020 \\
(0.044)\end{array}$ & $\begin{array}{c}0.024 \\
(0.027)\end{array}$ & $\begin{array}{l}-0.017 \\
(0.025)\end{array}$ & $\begin{array}{l}-0.030 \\
(0.043)\end{array}$ & $\begin{array}{c}0.039 \\
(0.023)\end{array}$ \\
\hline Stock Returns $_{i t}$ & $\begin{array}{c}-0.290^{* * * *} \\
(0.035)\end{array}$ & $\begin{array}{l}-0.119 \\
(0.071)\end{array}$ & $\begin{array}{c}-0.402 * * * \\
(0.046)\end{array}$ & $\begin{array}{c}-0.232 * * \\
(0.090)\end{array}$ & $\begin{array}{c}-0.297 * * * \\
(0.035)\end{array}$ & $\begin{array}{l}-0.106 \\
(0.097)\end{array}$ \\
\hline Stock Returns $_{i t} \times E$ & $\begin{array}{c}-0.175^{* * * *} \\
(0.039)\end{array}$ & $\begin{array}{c}-0.165^{* *} * \\
(0.060)\end{array}$ & $\begin{array}{c}-0.090 * * \\
(0.039)\end{array}$ & $\begin{array}{c}-0.269^{* * * *} \\
(0.084)\end{array}$ & $\begin{array}{c}-0.178 * * * \\
(0.040)\end{array}$ & $\begin{array}{c}-0.282^{* * * *} \\
(0.090)\end{array}$ \\
\hline$\Delta \log (\mathrm{VIX})_{t}$ & $\begin{array}{c}0.064 * * * \\
(0.004)\end{array}$ & $\begin{array}{c}0.054 * * * \\
(0.009)\end{array}$ & $\begin{array}{c}0.069 * * * \\
(0.007)\end{array}$ & $\begin{array}{c}0.069 * * * \\
(0.009)\end{array}$ & $\begin{array}{c}0.063 * * * \\
(0.004)\end{array}$ & $\begin{array}{c}0.070 * * * \\
(0.010)\end{array}$ \\
\hline$\Delta \log \left(\mathrm{VIX}_{t}\right) \times E$ & $\begin{array}{c}0.040 * * * \\
(0.005)\end{array}$ & $\begin{array}{c}0.010 \\
(0.008)\end{array}$ & $\begin{array}{c}0.036^{* * * *} \\
(0.007)\end{array}$ & $\begin{array}{c}0.011 \\
(0.010)\end{array}$ & $\begin{array}{c}0.040^{* * * *} \\
(0.005)\end{array}$ & $\begin{array}{c}0.024 \\
(0.015)\end{array}$ \\
\hline $\mathrm{E}$ & $\begin{array}{c}0.001 * * * \\
(0.000)\end{array}$ & $\begin{array}{l}-0.000 \\
(0.000)\end{array}$ & $\begin{array}{c}0.001 * * * \\
(0.000)\end{array}$ & $\begin{array}{l}-0.000 \\
(0.000)\end{array}$ & $\begin{array}{c}0.001 * * * \\
(0.000)\end{array}$ & $\begin{array}{c}0.001 \\
(0.001)\end{array}$ \\
\hline Constant & $\begin{array}{c}-0.001 * * * \\
(0.000)\end{array}$ & $\begin{array}{c}-0.000 * * \\
(0.000)\end{array}$ & $\begin{array}{c}-0.001^{* * * *} \\
(0.000)\end{array}$ & $\begin{array}{c}-0.001^{* *} \\
(0.000)\end{array}$ & $\begin{array}{c}-0.001^{* * * *} \\
(0.000)\end{array}$ & $\begin{array}{c}-0.001 * * \\
(0.000)\end{array}$ \\
\hline Firm FE & Yes & Yes & Yes & Yes & Yes & Yes \\
\hline No. Obs. & 41,967 & 10,282 & 41,536 & 10,282 & 40,685 & 9,420 \\
\hline R-squared & 0.274 & 0.285 & 0.315 & 0.434 & 0.278 & 0.386 \\
\hline Firms & 99 & 24 & 98 & 24 & 96 & 22 \\
\hline$p$-value for $\left(\beta_{2}^{\text {Core }}=\beta_{2}^{\text {Periphery }}\right)$ & 0.0 & & & & & \\
\hline
\end{tabular}




\section{TABLE 3: Corporate-sovereign nexus, analysis by country and sector}

The table reports estimates from the panel regression in Eq.(1), relating changes in log corporate CDS spreads to changes in log CDS spreads of the corresponding sovereigns and firm-specific and aggregate variables separately for each of the nine countries in our sample in Panel A and for each sector (including financials, which are excluded from the analysis in Table 2) in Panel B. The dummy $E$ equals one during the COVID-19 period (defined as the days after February 24, 2020) and zero otherwise. The industry classification follows Refinitiv Eikon. Robust standard errors clustered at the firm level are reported in parentheses. One, two, and three asterisks denote statistical significance at the $0.10,0.05$, and 0.01 levels, respectively.

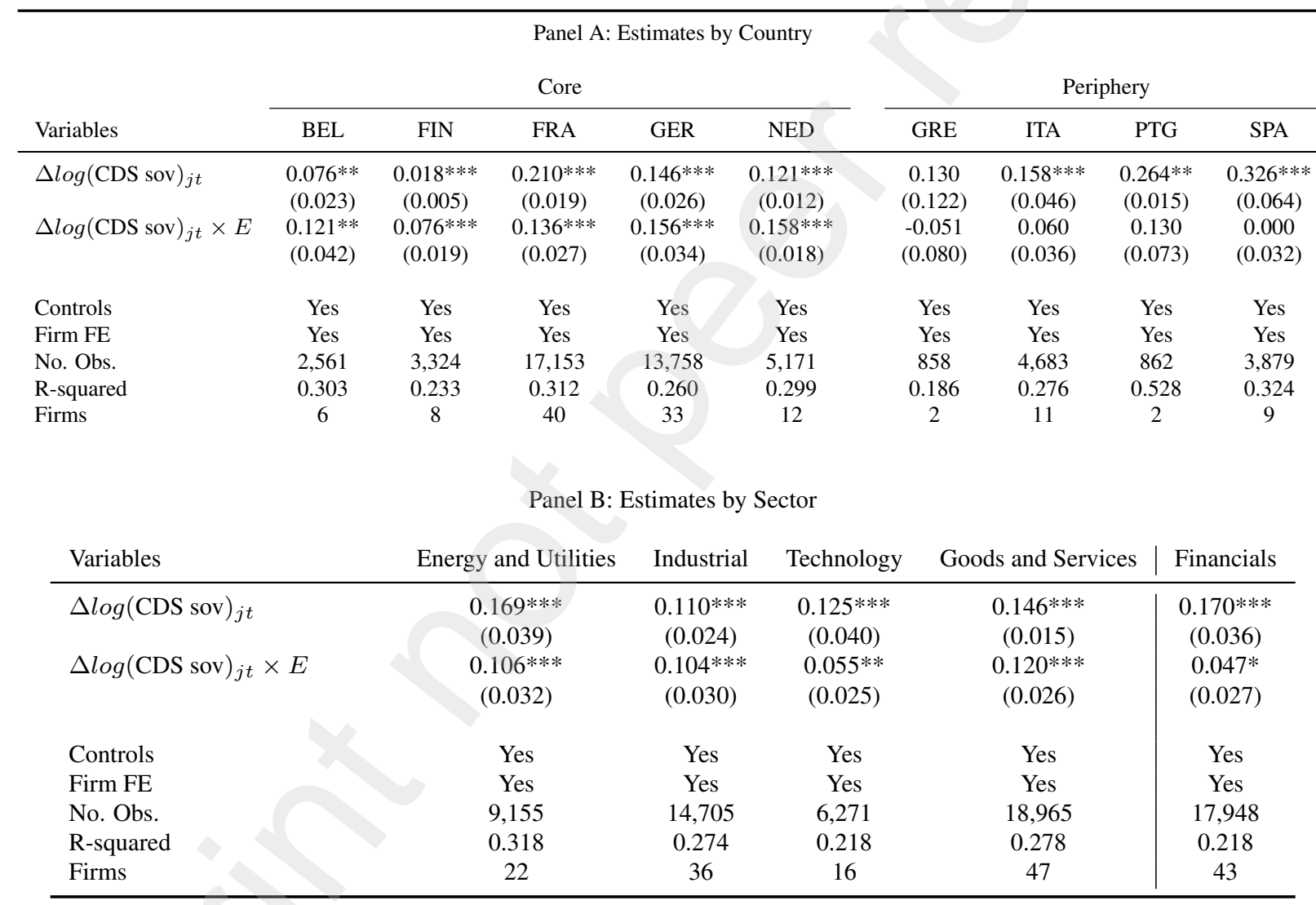




\section{TABLE 4: Corporate-sovereign nexus, robustness checks}

The table reports robustness checks from alternative specifications of the panel regression in Eq.(1), relating changes in log corporate CDS spreads to changes in $\log$ CDS spreads of the corresponding sovereigns and firm-specific and aggregate variables. The dummy $E$ equals one during the COVID-19 period (defined as the days after February 24, 2020) and zero otherwise. Results are reported including firm-level ATM option-implied volatility (columns 1 and 2), restricting the sample to the subset of issuers not eligible for the ECB Pandemic Emergency Purchase Programme (columns 3 and 4), and the disaster sample to one month after the Italian lockdown (columns 5 and 6), accounting for Nickell bias through the system GMM procedure of Arellano-Bover/Blundell-Bond (columns 7 and 8), estimating the model on weekly data (columns 9 and 10), and selecting the cum-restructuring clause for corporate CDS (columns 11 and 12). Robust standard errors clustered at the firm level are reported in parentheses. One, two, and three asterisks denote statistical significance at the $0.10,0.05$, and 0.01 levels, respectively.

(1)

(2)
(3)
(4)

(5)

(6)

\begin{tabular}{|c|c|c|c|c|c|c|}
\hline \multirow[b]{2}{*}{ Variables } & \multicolumn{2}{|c|}{ Implied Volatility } & \multicolumn{2}{|c|}{ Non-PEPP } & \multicolumn{2}{|c|}{ End March 24, 2020} \\
\hline & Core & Periphery & Core & Periphery & Core & Periphery \\
\hline$\Delta \log (\text { CDS Sov })_{j t}$ & $\begin{array}{c}0.132 * * * \\
(0.014)\end{array}$ & $\begin{array}{c}0.219 * * * \\
(0.041)\end{array}$ & $\begin{array}{l}0.073 * * \\
(0.031)\end{array}$ & $\begin{array}{c}0.186 * * * \\
(0.045)\end{array}$ & $\begin{array}{c}0.127 * * * \\
(0.013)\end{array}$ & $\begin{array}{c}0.208 * * * * \\
(0.036)\end{array}$ \\
\hline$\Delta \log (\text { CDS Sov })_{j t} \times E$ & $\begin{array}{c}0.125 * * * \\
(0.016)\end{array}$ & $\begin{array}{c}0.032 \\
(0.036)\end{array}$ & $\begin{array}{l}0.109 * * \\
(0.047)\end{array}$ & $\begin{array}{c}0.065 \\
(0.049)\end{array}$ & $\begin{array}{c}0.153 * * * \\
(0.020)\end{array}$ & $\begin{array}{c}0.058 \\
(0.041)\end{array}$ \\
\hline Controls & Yes & Yes & Yes & Yes & Yes & Yes \\
\hline Firm FE & Yes & Yes & Yes & Yes & Yes & Yes \\
\hline No. Obs. & 38,297 & 8,374 & 10,582 & 5,579 & 30,273 & 7,480 \\
\hline R-squared & 0.286 & 0.279 & 0.224 & 0.246 & 0.330 & 0.313 \\
\hline \multirow[t]{3}{*}{ Firms } & 92 & 20 & 25 & 13 & 99 & 24 \\
\hline & (7) & (8) & (9) & (10) & (11) & (12) \\
\hline & \multicolumn{2}{|c|}{ Arellano-Bover/Blundell-Bond } & \multicolumn{2}{|c|}{ Weekly Aggregation } & \multicolumn{2}{|c|}{ CR Clause } \\
\hline Variables & Core & Periphery & Core & Periphery & Core & Periphery \\
\hline$\Delta \log (\mathrm{CDS} \mathrm{Sov})_{j t}$ & $0.135 * * *$ & $0.268 * * *$ & $0.149 * * *$ & $0.161 * * *$ & $0.134 * * *$ & $0.246 * * *$ \\
\hline$\Delta \log (\text { CDS Sov })_{j t} \times E$ & $\begin{array}{c}0.159 * * * \\
(0.021)\end{array}$ & $\begin{array}{l}-0.013 \\
(0.031)\end{array}$ & $\begin{array}{c}0.155 * * * \\
(0.030)\end{array}$ & $\begin{array}{c}0.071 \\
(0.044)\end{array}$ & $\begin{array}{c}0.127 * * * \\
(0.014)\end{array}$ & $\begin{array}{c}0.006 \\
(0.033)\end{array}$ \\
\hline Controls & Yes & Yes & Yes & Yes & Yes & Yes \\
\hline Firm FE & Yes & Yes & Yes & Yes & Yes & Yes \\
\hline No. Obs. & 32,957 & 8,096 & 8,458 & 2,075 & 35,848 & 7,319 \\
\hline R-squared & - & - & 0.405 & 0.376 & 0.288 & 0.330 \\
\hline Firms & 99 & 24 & 99 & 24 & 84 & 17 \\
\hline
\end{tabular}




\section{TABLE 5: Corporate-sovereign nexus, firm-level controls}

The table reports estimates from the panel regression in Eq. (1), where the covariates are augmented with firm-specific characteristics that proxy for firm sensitivity to the shock. The dummy $E$ equals one during the COVID-19 period (defined as the days after February 24, 2020) and zero otherwise. Columns (1) and (2) augment the baseline regression with profit per employee (profit before taxes over employees). Columns (3) and (4) control for the liquidity ratio (current assets minus stocks divided by current liabilities). Columns (5) and (6) account for loans (log of loans from financial institutions divided by total debt). Following standard practice, all ratios are industry-year adjusted. The ratios enter the regression in level and interacted with changes in sovereign CDS spreads. The models are estimated separately for core countries (Belgium, Finland, France, Germany, and the Netherlands) and periphery countries (Greece, Italy, Portugal, and Spain). Robust standard errors clustered at the firm level are reported in parentheses. One, two, and three asterisks denote statistical significance at the $0.10,0.05$, and 0.01 levels, respectively.

\begin{tabular}{|c|c|c|c|c|c|c|}
\hline \multirow[b]{3}{*}{ Variables } & (1) & (2) & (3) & (4) & (5) & (6) \\
\hline & Core & Periphery & Core & Periphery & Core & Periphery \\
\hline & \multicolumn{2}{|c|}{$Z=P P E$} & \multicolumn{2}{|c|}{$Z=$ Liquidity } & \multicolumn{2}{|c|}{$Z=$ Loans } \\
\hline$\Delta \log (\mathrm{CDS} \text { sovereign })_{j t}$ & $\begin{array}{c}0.142 * * * \\
(0.013)\end{array}$ & $\begin{array}{c}0.253^{* * * *} \\
(0.060)\end{array}$ & $\begin{array}{c}0.136 * * * \\
(0.013)\end{array}$ & $\begin{array}{c}0.216^{* * * *} \\
(0.038)\end{array}$ & $\begin{array}{c}0.136 * * * \\
(0.013)\end{array}$ & $\begin{array}{c}0.207 * * * * \\
(0.040)\end{array}$ \\
\hline$\Delta \log (\mathrm{CDS} \text { sovereign })_{j t} \times E$ & $\begin{array}{c}0.114 * * * \\
(0.014)\end{array}$ & $\begin{array}{c}0.045 \\
(0.041)\end{array}$ & $\begin{array}{c}0.120 * * * \\
(0.014)\end{array}$ & $\begin{array}{c}0.063 \\
(0.039)\end{array}$ & $\begin{array}{c}0.117 * * * \\
(0.015)\end{array}$ & $\begin{array}{c}0.056 \\
(0.037)\end{array}$ \\
\hline $\mathrm{Z}_{i t}$ & $\begin{array}{l}-0.000 \\
(0.000)\end{array}$ & $\begin{array}{l}-0.001 \\
(0.001)\end{array}$ & $\begin{array}{c}0.000 \\
(0.000)\end{array}$ & $\begin{array}{c}0.000 \\
(0.001)\end{array}$ & $\begin{array}{c}-0.003 \\
(0.003)\end{array}$ & $\begin{array}{c}-0.002 \\
(0.004)\end{array}$ \\
\hline $\mathrm{Z}_{i t} \times E$ & $\begin{array}{l}-0.000 \\
(0.000)\end{array}$ & $\begin{array}{l}-0.001 \\
(0.001)\end{array}$ & $\begin{array}{l}-0.000 \\
(0.000)\end{array}$ & $\begin{array}{l}-0.002^{*} \\
(0.001)\end{array}$ & $\begin{array}{c}0.003 \\
(0.002)\end{array}$ & $\begin{array}{c}0.008 \\
(0.009)\end{array}$ \\
\hline$\Delta \log (\mathrm{CDS} \text { sovereign })_{j t} \times Z_{i t}$ & $\begin{array}{c}-0.009 * * * \\
(0.003)\end{array}$ & $\begin{array}{l}-0.023 \\
(0.031)\end{array}$ & $\begin{array}{c}-0.015 * * * \\
(0.002)\end{array}$ & $\begin{array}{c}0.028 \\
(0.030)\end{array}$ & $\begin{array}{c}0.172 \\
(0.176)\end{array}$ & $\begin{array}{l}-0.403 \\
(0.404)\end{array}$ \\
\hline$\Delta \log (\mathrm{CDS} \text { sovereign })_{j t} \times Z_{i t} \times E$ & $\begin{array}{c}0.027 \\
(0.031)\end{array}$ & $\begin{array}{c}0.135 \\
(0.140)\end{array}$ & $\begin{array}{c}-0.009 * * * \\
(0.003)\end{array}$ & $\begin{array}{l}0.185^{* *} \\
(0.068)\end{array}$ & $\begin{array}{c}0.088 \\
(0.676)\end{array}$ & $\begin{array}{l}-0.595 \\
(1.539)\end{array}$ \\
\hline Firm FE & Yes & Yes & Yes & Yes & Yes & Yes \\
\hline Controls & Yes & Yes & Yes & Yes & Yes & Yes \\
\hline No. Obs. & 35,498 & 8,479 & 36,282 & 8,833 & 35,420 & 8,833 \\
\hline R-squared & 0.283 & 0.323 & 0.282 & 0.330 & 0.279 & 0.331 \\
\hline Firms & 85 & 21 & 86 & 21 & 84 & 21 \\
\hline
\end{tabular}




\section{TABLE 6: Corporate-sovereign nexus, country-level controls}

The table reports estimates from the panel regression in Eq. (1), where the covariates are augmented with country-specific characteristics. The dummy $E$ equals one during the COVID-19 period (defined as the days after February 24, 2020) and zero otherwise. Results are augmented with country-specific characteristics from the OECD, World Bank, and Oxford COVID-19 Government Response Tracker databases. Column 1 reports the baseline model jointly estimated on core (Belgium, Finland, France, Germany, and the Netherlands) and periphery (Greece, Italy, Portugal, and Spain) countries. In Column 2, trade openness (measured as import plus exports over GDP) is added to the baseline regression. Column 3 controls for the number of hospital beds per thousand inhabitants. Column 4 includes the share of GDP generated by tourism per country and year. Columns 6 and 7 saturate the baseline model with week $\times$ sector and week $\times$ country fixed effects. Robust standard errors clustered at the firm level are reported in parentheses. One, two, and three asterisks denote statistical significance at the $0.10,0.05$, and 0.01 levels, respectively.

\begin{tabular}{|c|c|c|c|c|c|c|c|}
\hline Variables & (1) & (2) & (3) & (4) & (5) & (6) & (7) \\
\hline Core $_{i} \times \Delta \log (\text { CDS sovereign })_{j t}$ & $\begin{array}{l}-0.061 \\
(0.044)\end{array}$ & $\begin{array}{l}-0.061 \\
(0.044)\end{array}$ & $\begin{array}{l}-0.061 \\
(0.044)\end{array}$ & $\begin{array}{l}-0.059 \\
(0.044)\end{array}$ & $\begin{array}{l}-0.061 \\
(0.044)\end{array}$ & $\begin{array}{l}-0.052 \\
(0.043)\end{array}$ & $\begin{array}{c}-0.094 * * \\
(0.044)\end{array}$ \\
\hline Core $_{i} \times \Delta \log (\text { CDS sovereign })_{j t} \times E$ & $\begin{array}{c}0.113 * * * \\
(0.039)\end{array}$ & $\begin{array}{c}0.113 * * * \\
(0.039)\end{array}$ & $\begin{array}{c}0.113 * * * * \\
(0.039)\end{array}$ & $\begin{array}{c}0.109 * * * \\
(0.039)\end{array}$ & $\begin{array}{c}0.113^{* * *} * \\
(0.039)\end{array}$ & $\begin{array}{c}0.095 * * \\
(0.038)\end{array}$ & $\begin{array}{c}0.119 * * * * \\
(0.043)\end{array}$ \\
\hline$\Delta \log (\mathrm{CDS} \text { sovereign })_{j t} \times E$ & $\begin{array}{c}0.020 \\
(0.036)\end{array}$ & $\begin{array}{c}0.020 \\
(0.036)\end{array}$ & $\begin{array}{c}0.020 \\
(0.036)\end{array}$ & $\begin{array}{c}0.020 \\
(0.036)\end{array}$ & $\begin{array}{c}0.020 \\
(0.036)\end{array}$ & $\begin{array}{l}0.060^{*} \\
(0.034)\end{array}$ & $\begin{array}{c}0.049 \\
(0.038)\end{array}$ \\
\hline$\Delta \log (\mathrm{CDS} \text { sovereign })_{j t}$ & $\begin{array}{c}0.189 * * * \\
(0.041)\end{array}$ & $\begin{array}{c}0.189 * * * \\
(0.041)\end{array}$ & $\begin{array}{c}0.189 * * * \\
(0.041)\end{array}$ & $\begin{array}{c}0.187 * * * \\
(0.041)\end{array}$ & $\begin{array}{c}0.189 * * * \\
(0.041)\end{array}$ & $\begin{array}{c}0.149 * * * \\
(0.041)\end{array}$ & $\begin{array}{c}0.193 * * * \\
(0.042)\end{array}$ \\
\hline Trade Openness $_{j t}$ & & $\begin{array}{c}0.000 \\
(0.000)\end{array}$ & & & & & \\
\hline Hospital Beds $_{j t}$ & & & $\begin{array}{l}-0.001 \\
(0.003)\end{array}$ & & & & \\
\hline 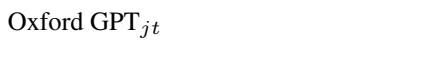 & & & & $\begin{array}{c}-0.000^{* * * *} \\
(0.000)\end{array}$ & & & \\
\hline Tourism $_{j t}$ & & & & & $\begin{array}{l}-0.000 \\
(0.001)\end{array}$ & & \\
\hline Firm FE & Yes & Yes & Yes & Yes & Yes & Yes & Yes \\
\hline Week × Sector FE & No & No & No & No & No & Yes & No \\
\hline Week $\times$ Country FE & No & No & No & No & No & No & Yes \\
\hline Controls & Yes & Yes & Yes & Yes & Yes & Yes & Yes \\
\hline No. Obs & 52,249 & 52,249 & 52,249 & 52,249 & 52,249 & 52,249 & 52,249 \\
\hline $\mathrm{R}$-squared & 0.272 & 0.272 & 0.272 & 0.275 & 0.272 & 0.322 & 0.319 \\
\hline Firms & 123 & 123 & 123 & 123 & 123 & 123 & 123 \\
\hline
\end{tabular}



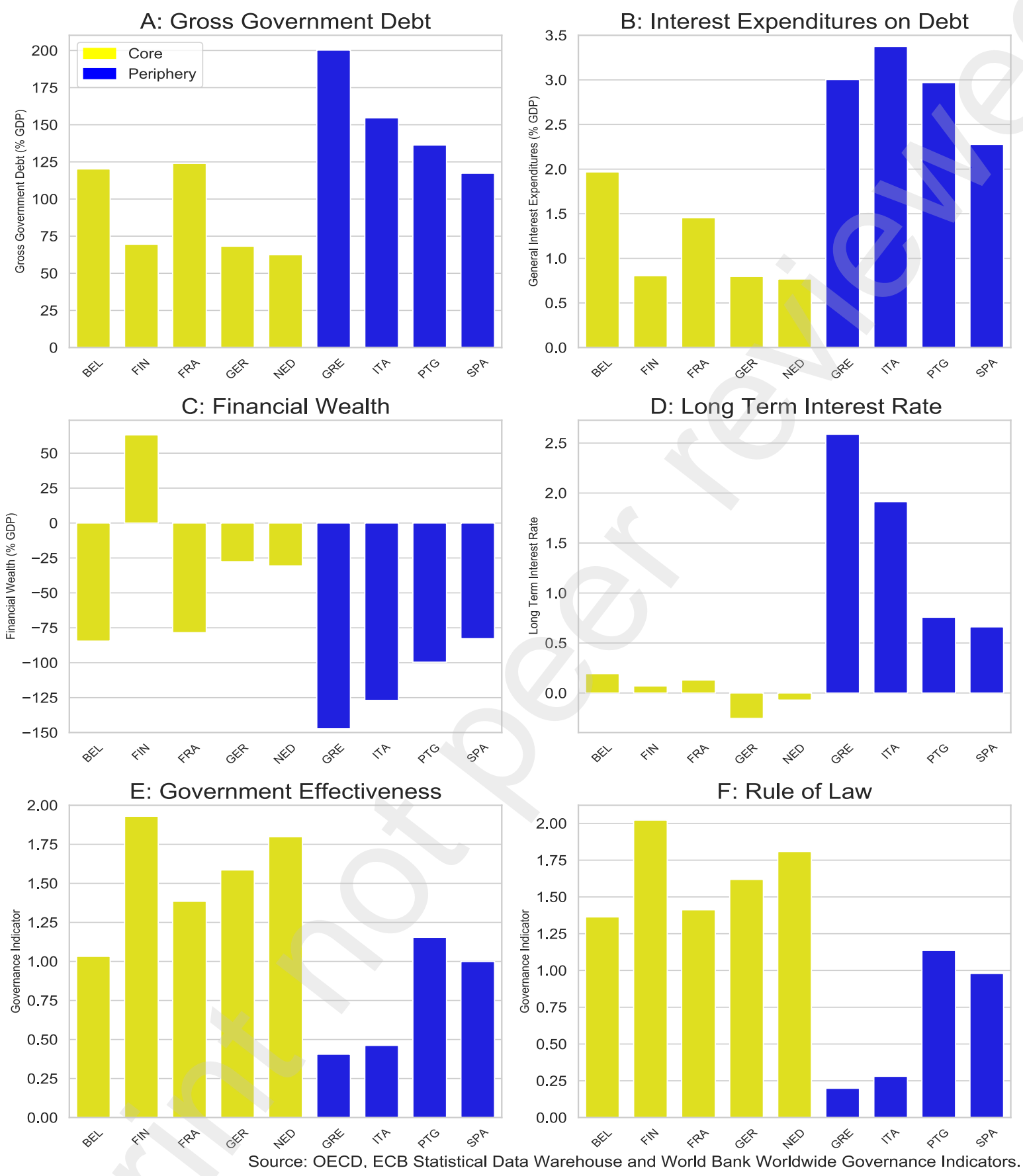

FIgURE A.1: Fiscal capacity measures: This figure plots several proxies for fiscal capacity for the nine Euro Area countries included in the sample. Panel A reports gross government debt over GDP. Panel B considers interest expenditures on debt over GDP. Panel C represents financial wealth, defined as financial assets minus outstanding liabilities. Panel D displays bond implied long-term interest rates. Panels E and F report, respectively, World Bank indexes for government effectiveness, e.g., quality of policy, and rule of law, e.g., enforcement of property rights. 


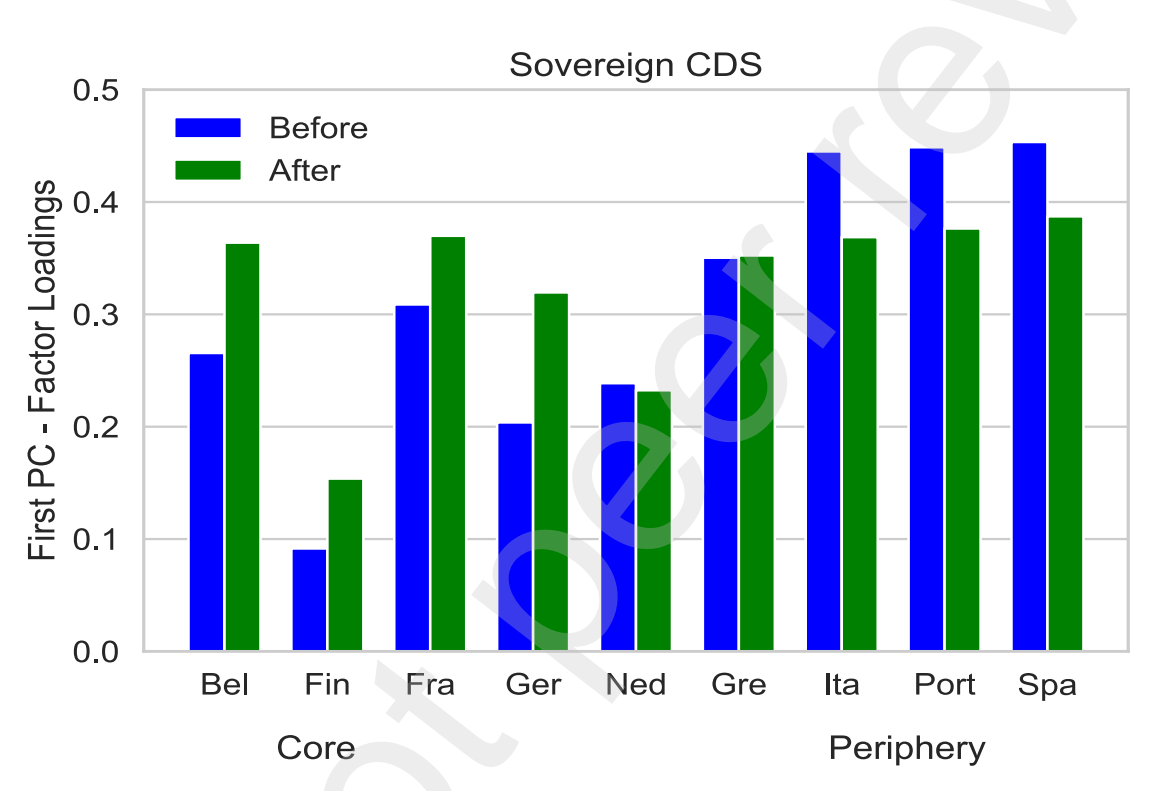

FIGURE A.2: Loadings for the first principal component of sovereign CDS spreads: This figure plots the loadings of the first principal component of standardized sovereign CDS spreads on each of the nine countries in the sample, before and after the onset of the pandemic in Europe on February 24, 2020. 


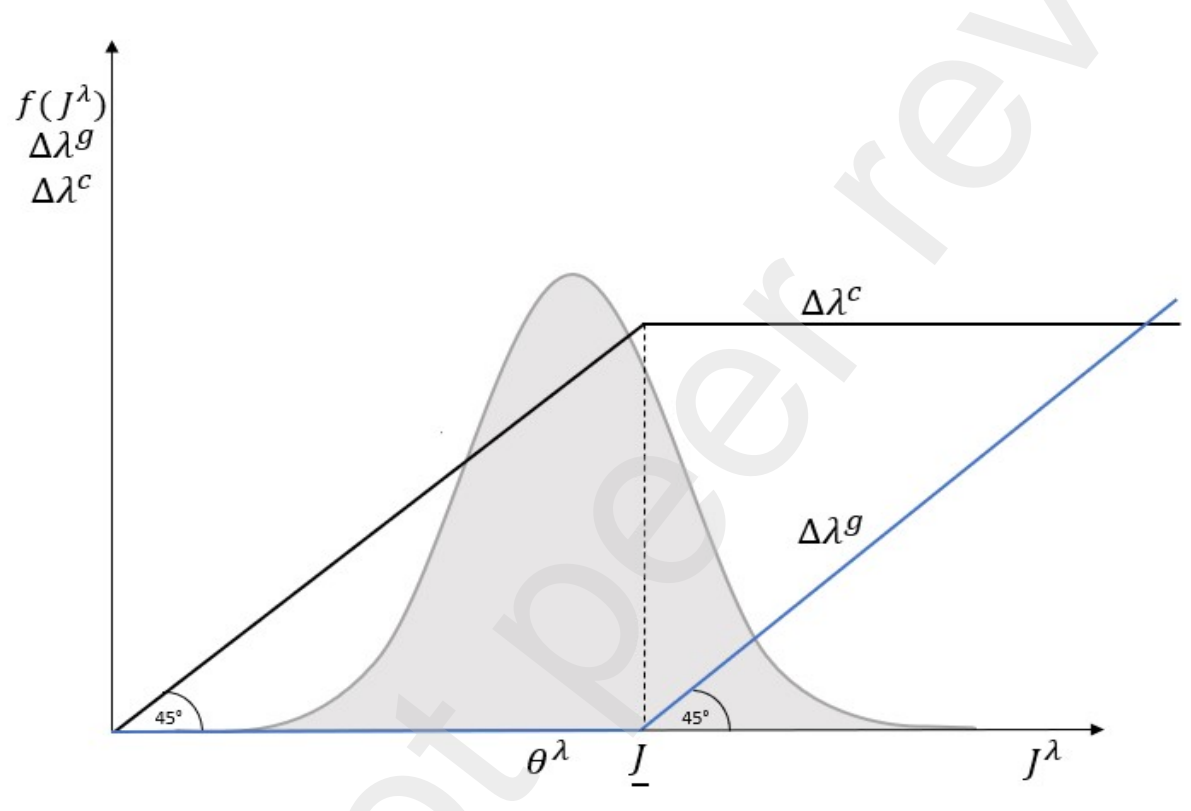

FIGURE A.3: Government bailout policy: This figure plots increases in default intensities of claims referenced on corporate and government entities conditionally on the occurrence of a disaster $J^{\lambda}$, whose probability distribution is represented by the gray shaded area. All the losses below $\underline{J}$ are borne by the private sector alone, to reflect the idea that governments intervene for severe catastrophes, in which case default intensity for the private sector is capped. 


\section{TABLE A.1: Top 100 non-financial firms}

This table reports the top 100 non-financial firms by market capitalization (as of the end of 2019) in our sample. Source: Markit and Refinitiv.

\begin{tabular}{|c|c|c|c|c|c|}
\hline Name & Country & Rank & Name & Country & Rank \\
\hline LVMH & France & 1 & Michelin & France & 51 \\
\hline L'Oréal & France & 2 & Legrand & France & 52 \\
\hline SAP SE & Germany & 3 & Peugeot S.A & France & 53 \\
\hline Anheuser-Busch InBev & Belgium & 4 & Nokia Oyj & Finland & 54 \\
\hline Total SE & France & 5 & Capgemini SE & France & 55 \\
\hline Sanofi & France & 6 & Akzo Nobel N.V. & Netherlands & 56 \\
\hline Airbus Group & Netherlands & 7 & Wolters Kluwer N.V. & Netherlands & 57 \\
\hline Volkswagen Group & Germany & 8 & Atlantia S.p.A. & Italy & 58 \\
\hline Siemens AG & Germany & 9 & UPM-Kymmene Oyj & Finland & 59 \\
\hline Kering & France & 10 & Sodexo & France & 60 \\
\hline Enel S.p.A. & Italy & 11 & Cellnex Telecom SA & Spain & 61 \\
\hline Bayer AG & Germany & 12 & Bouygues & France & 62 \\
\hline Deutsche Telekom AG & Germany & 13 & EDP - Energias de Portugal & Portugal & 63 \\
\hline BASF SE & Germany & 14 & EnBW Energie Baden-Württemberg AG & Germany & 64 \\
\hline Air Liquide & France & 15 & Hapag-Lloyd AG & Germany & 65 \\
\hline Iberdrola & Spain & 16 & $\mathrm{UCB}$ & Belgium & 66 \\
\hline Adidas AG & Germany & 17 & CNH Industrial N.V. & Netherlands & 67 \\
\hline Vinci SA & France & 18 & Veolia Environnement S.A. & France & 68 \\
\hline Heineken N.V. & Netherlands & 19 & HeidelbergCement AG & Germany & 69 \\
\hline Daimler AG & Germany & 20 & Galp Energia SGPS S.A. & Portugal & 70 \\
\hline Schneider Electric SE & France & 21 & Groupe Renault & France & 71 \\
\hline Eni S.p.A. & Italy & 22 & Terna - Rete Elettrica Nazionale S.p.A. & Italy & 72 \\
\hline BMW Group & Germany & 23 & Carrefour S.A. & France & 73 \\
\hline Danone & France & 24 & Telecom Italia S.p.A. & Italy & 74 \\
\hline Merck KGaA & Germany & 25 & Accor S.A. & France & 75 \\
\hline Pernod Ricard & France & 26 & Koninklijke KPN N.V. & Netherlands & 76 \\
\hline Deutsche Post AG & Germany & 27 & Solvay S.A. & Belgium & 77 \\
\hline Henkel AG \& Co. KGaA & Germany & 28 & Stora Enso Oyj & Finland & 78 \\
\hline Koninklijke Philips N.V. & Netherlands & 29 & Red Eléctrica de España & Spain & 79 \\
\hline Orange & France & 30 & Publicis Groupe & France & 80 \\
\hline Engie & France & 31 & Alstom SA & France & 81 \\
\hline Telefónica & Spain & 32 & Proximus & Belgium & 82 \\
\hline Électricité de France & France & 33 & Hochtief AG & Germany & 83 \\
\hline Vivendi & France & 34 & ThyssenKrupp AG & Germany & 84 \\
\hline Fresenius SE \& Co. KGaA & Germany & 35 & Elisa Oyj & Finland & 85 \\
\hline Fiat Chrysler Automobiles N.V. & Netherlands & 36 & Deutsche Lufthansa AG & Germany & 86 \\
\hline Endesa S.A. & Spain & 37 & Valeo & France & 87 \\
\hline E.ON SE & Germany & 38 & Hellenic Telecommunications Organization S.A. & Greece & 88 \\
\hline Koninklijke Ahold Delhaize N.V. & Netherlands & 39 & Faurecia & France & 89 \\
\hline Continental AG & Germany & 40 & Schaeffler Group & Germany & 90 \\
\hline Naturgy Energy Group S.A & Spain & 41 & MAN SE & Germany & 91 \\
\hline Grifols S.A. & Spain & 42 & TUI Group & Germany & 92 \\
\hline STMicroelectronics N.V. & Netherlands & 43 & Leonardo S.p.A. & Italy & 93 \\
\hline Porsche Automobil Holding SE & Germany & 44 & Rémy Cointreau & France & 94 \\
\hline Repsol S.A. & Spain & 45 & Edison S.p.A. & Italy & 95 \\
\hline Koninklijke DSM N.V. & Netherlands & 46 & Elia System Operator & Belgium & 96 \\
\hline Compagnie de Saint-Gobain S.A. & France & 47 & Metso & Finland & 97 \\
\hline Thales Group & France & 48 & Pirelli \& C. S.p.A. & Italy & 98 \\
\hline Fresenius Medical Care AG \& Co. KGaA & Germany & 49 & Lanxess AG & Germany & 99 \\
\hline Fortum Oyj & Finland & 50 & Casino Guichard-Perrachon & France & 100 \\
\hline
\end{tabular}




\section{TABLE A.2: Entropy-balancing covariates}

The table reports the first three moments of credit risk-relevant variables stratified by region of the Euro Area. Panel A presents unweighted summary statistics. Panel B shows the corresponding moments when each observation is reweighted, following Hainmueller (2012). Entropy balancing optimally determines weights to achieve exact moment matching while keeping the distribution of observations as close as possible to the data in an entropy sense.

\begin{tabular}{|c|c|c|c|c|c|c|}
\hline \multicolumn{7}{|c|}{ Panel A: Unweighted Sample } \\
\hline & \multicolumn{3}{|c|}{ Core } & \multicolumn{3}{|c|}{ Periphery } \\
\hline & Mean & Variance & Skewness & Mean & Variance & Skewness \\
\hline Market Capitalization & $3.03 \times 10^{7}$ & $1.40 \times 10^{15}$ & 2.332 & $1.90 \times 10^{7}$ & $3.34 \mathrm{e} \times 10^{14}$ & 1.538 \\
\hline Total Debt to Total Assets & 30.64 & 237 & 1.184 & 40.15 & 108.9 & -0.318 \\
\hline Equity Volatility (5-yr) & 0.264 & 0.005 & 0.853 & 0.245 & 0.006 & 1.964 \\
\hline \multirow[t]{3}{*}{ Market to Book } & 2.100 & 2.535 & 1.076 & 2.095 & 2.321 & 2.039 \\
\hline & \multicolumn{3}{|c|}{ Core } & \multicolumn{3}{|c|}{ Periphery } \\
\hline & Mean & Variance & Skewness & Mean & Variance & Skewness \\
\hline Market Capitalization & $3.03 \times 10^{7}$ & $1.40 \times 10^{15}$ & 2.332 & $3.03 \times 10^{7}$ & $6.30 \times 10^{14}$ & 0.4907 \\
\hline Total Debt to Total Assets & 30.64 & 237 & 1.184 & 30.66 & 84.82 & 0.4818 \\
\hline Equity Volatility (5-yr) & 0.264 & 0.005 & 0.853 & 0.264 & 0.012 & 1.230 \\
\hline Market to Book & 2.100 & 2.535 & 1.076 & 2.099 & 3.217 & 1.915 \\
\hline
\end{tabular}




\section{TABLE A.3: Principal component analysis}

The table reports the fraction of variance explained by the first two principal components extracted from the correlation matrix of daily differences in $\log$ CDS spreads on the panel of sovereign CDS spreads, corporate CDS spreads, and corporate stock returns. The event period $(E=1)$ corresponds to the days after February 24, 2020. The full sample runs from January 1, 2019 to September 10, 2020.

\begin{tabular}{lccc}
\hline & Event & \% Var. $1^{\text {st }}$ Comp. & \% Var. $2^{\text {nd }}$ Comp. \\
\hline Corporate CDS & $\mathrm{E}=0$ & 0.5402 & 0.0325 \\
Corporate CDS & $\mathrm{E}=1$ & 0.7049 & 0.0289 \\
\hline Sovereign CDS & $\mathrm{E}=0$ & 0.3382 & 0.1299 \\
Sovereign CDS & $\mathrm{E}=1$ & 0.6705 & 0.1064 \\
\hline Stock Market & $\mathrm{E}=0$ & 0.2718 & 0.0767 \\
Stock Market & $\mathrm{E}=1$ & 0.5319 & 0.0690 \\
\hline
\end{tabular}

\section{TABLE A.4: Controlling for squared equity returns}

The table reports estimates from the baseline panel regression, including a quadratic term in firm-level stock returns. Results are reported for the equally weighted model (columns 1 and 2), the equity market capitalization-weighted model (columns 3 and 4 ), and the entropy-balanced specification ensuring covariate comparability (columns 5 and 6). Robust standard errors clustered at the firm level are in parentheses. One, two, and three asterisks denote statistical significance at the $0.10,0.05$, and 0.01 levels, respectively.

\begin{tabular}{|c|c|c|c|c|c|c|}
\hline & \multicolumn{2}{|c|}{ Equally Weighted } & \multicolumn{2}{|c|}{ Value Weighted } & \multicolumn{2}{|c|}{ Entropy Balanced } \\
\hline & (1) & (2) & (3) & (4) & (5) & (6) \\
\hline$\Delta \log (\mathrm{CDS} \text { sovereign })_{j t}$ & $\begin{array}{c}0.127 * * * \\
(0.013)\end{array}$ & $\begin{array}{c}0.208 * * * \\
(0.036)\end{array}$ & $\begin{array}{c}0.169 * * * \\
(0.015)\end{array}$ & $\begin{array}{c}0.326 * * * \\
(0.037)\end{array}$ & $\begin{array}{c}0.127 * * * \\
(0.013)\end{array}$ & $\begin{array}{c}0.294 * * * \\
(0.040)\end{array}$ \\
\hline$\Delta \log (\mathrm{CDS} \text { sovereign })_{j t} \times E$ & $\begin{array}{c}0.115 * * * \\
(0.016)\end{array}$ & $\begin{array}{c}0.042 \\
(0.029)\end{array}$ & $\begin{array}{c}0.138^{* * * *} \\
(0.023)\end{array}$ & $\begin{array}{c}0.029 \\
(0.031)\end{array}$ & $\begin{array}{c}0.115^{* * * *} \\
(0.016)\end{array}$ & $\begin{array}{c}0.003 \\
(0.036)\end{array}$ \\
\hline Stock Returns ${ }_{i j t}^{2}$ & Yes & Yes & Yes & Yes & Yes & Yes \\
\hline Controls & Yes & Yes & Yes & Yes & Yes & Yes \\
\hline Firm FE & Yes & Yes & Yes & Yes & Yes & Yes \\
\hline Observations & 41,967 & 10,282 & 41,536 & 10,282 & 40,685 & 9,420 \\
\hline R-squared & 0.285 & 0.294 & 0.323 & 0.443 & 0.290 & 0.404 \\
\hline Firms & 99 & 24 & 98 & 24 & 96 & 22 \\
\hline
\end{tabular}




\section{Swiss Finance Institute}

Swiss Finance Institute (SFI) is the national center for fundamental research, doctoral training, knowledge exchange, and continuing education in the fields of banking and finance. SFI's mission is to grow knowledge capital for the Swiss financial marketplace. Created in 2006 as a public-private partnership, SFI is a common initiative of the Swiss finance industry, leading Swiss universities, and the Swiss Confederation.

\section{Swiss : finance: institute}

c/o University of Geneva, Bd. Du Pont d'Arve 42, CH-1211 Geneva 4 T+41 2237984 71, rps@sfi.ch,www.sfi.ch 


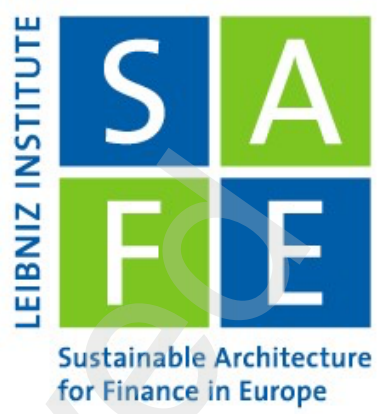

\section{Recent Issues}

No. 330 Jan Krzyzanowski, Uwe Walz

No. 329 Jana Eisenkopf, Steffen Juranek, Uwe Walz

No. 328 Hoang Ha Nguyen Thi, Alfons Weichenrieder

No. $327 \quad$ Fincap team

No. 326 Wenhui Li, Peter Ockenfels, Christian Wilde

No. 325 Alperen A. Gözlügöl

No. 324 Massimiliano Caporina, Michele Costola

No. 323 Alexandre Corhay, Thilo Kind, Howard Kung, Gonzalo Morales

No. 322 Gianluca Anese, Marco Corazza, Michele Costola, Loriana Pelizzon

No. 321 Ignazio Angeloni, Johannes Kasinger, Chantawit Tantasith

No. 320 Sebastian Steuer, Tobias H. Tröger

No. 319 Erik Theissen, Christian Westheide

No. 318 Kevin Bauer, Michael Kosfeld, Ferdinand von Siemens

No. 317 Volker Flögel, Christian Schlag, Claudia Zunft

No. 316 Christian Mücke, Loriana Pelizzon, Vincenzo Pezone, Anjan Thako
Bank Regulation, Lending and Patenting: Evidence from the EBA Capital Exercise

Responsible Investment and Stock Market Shocks: Short-Term Insurance and Persistent Outperformance Post-Crisis?

C and S Corporation Banks: Did Trump's Tax Reform Lead to Differential Effects?

Non-Standard Errors

The Effect of Ambiguity on Price Formation and Trading Behavior in Financial Markets

The Clash of 'E' and 'S' of ESG:

Just Transition on the Path to Net Zero and the Implications for Sustainable Corporate Governance and Finance

Time-Varying Granger Causality Tests for Applications in Global Crude Oil Markets: A Study on the DCC-MGARCH Hong Test

Discount Rates, Debt Maturity, and the Fiscal Theory

Impact of Public News Sentiment on Stock Market Index Return and Volatility

The Geography of Banks in the United States (1990-2020)

The Role of Disclosure in Green Finance

Call of Duty: Designated Market Maker Participation in Call Auctions

Incentives, Self-Selection, and Coordination of Motivated Agents for the Production of Social Goods

Momentum-Managed Equity Factors

The Carrot and the Stick: Bank Bailouts and the Disciplining Role of Board Appointments 